\title{
Origin of Zoned Metal Grains in the QUE94411 Chondrite
}

\author{
ANDREW J. CAMPBELL ${ }^{*}, 1$, MUNIR HUMAYUN ${ }^{1}$, ANDERS MEIBOM $^{2,3}$, \\ ALEXANDER N. KROT ${ }^{2}$, AND KLAUS KEIL ${ }^{2}$ \\ ${ }^{1}$ Department of the Geophysical Sciences, The University of Chicago, Chicago, Illinois \\ 60637, USA \\ ${ }^{2}$ Hawai'i Institute of Geophysics and Planetology, School of Ocean and Earth Science and \\ Technology, University of Hawai'i at Manoa, Honolulu, Hawai'i 96822, USA \\ ${ }^{3}$ Present address: Geological and Environmental Sciences, Stanford University, Palo Alto, \\ California 94305, USA \\ *email: acampbel@midway.uchicago.edu \\ ph: (773) 834-1523, fax: (773) 702-9505
}

Submitted to Geochim. Cosmochim. Acta, 10 May 2000

\#W0332: Revised 1 August 2000, Accepted 7 August 2000 


\begin{abstract}
Laser ablation ICP mass spectrometry was used to measure distributions of the siderophile elements $\mathrm{P}, \mathrm{V}, \mathrm{Cr}, \mathrm{Fe}, \mathrm{Co}, \mathrm{Ni}, \mathrm{Mo}, \mathrm{Ru}, \mathrm{Rh}, \mathrm{Pd}, \mathrm{W}, \mathrm{Re}$, Os, Ir, and Pt in metal grains in the metal-rich chondrite QUE94411 with a spatial resolution of $\sim 30 \mu \mathrm{m}$. The platinum group elements (PGEs), with the exception of Pd, exhibit radial zoning in these grains that mimics that previously observed in $\mathrm{Ni}$ and $\mathrm{Co}$; the concentrations of these elements decreases from the cores to the rims of the grains. The PGE distributions support a condensation origin for the enhanced refractory element abundances in the zoned grains; the lack of zoning in Pd refutes an origin by a redoxcontrolled process, and none of the PGE-Ni relationships support an origin by fractional crystallization from a metallic melt. Several models of grain formation are explored, including equilibrium fractional condensation, which fails to yield the correct radial zoning. The zoning may be the product of a nonequilibrium fractional condensation process, in which the refractory siderophiles remained supersaturated in the cooling solar nebula, or of diffusion between refractory-enhanced Fe-Ni cores and other Fe-Ni metal that may have been deposited later from the solar nebula.
\end{abstract}




\section{INTRODUCTION}

A substantial proportion of the material that constitutes meteorites and planets shows evidence of chemical processing at high temperatures (Humayun and Cassen, 2000). Thermal models of solar nebula evolution (Morfill, 1985; Boss, 1993; Cassen, 1994) indicate the presence of a hot, central region with temperatures exceeding $1500 \mathrm{~K}$-the hot solar nebula of cosmochemistry. Material processed through this region would have been completely vaporized and subsequently recondensed upon cooling (Grossman and Larimer, 1974). Most studies of potential condensate grains in meteorites have focussed on silicates (Grossman, 1972; 1980; Steele, 1988) and refractory CAI metal, or Fremdlinge (Palme and Wlotzka, 1976; Sylvester et al., 1990). Metallic grains constitute an important complent to refractory silicates in primitive chondrites. The compositions of metal grains formed by condensation from a hot solar nebula were calculated by Grossman and Olsen (1974), and several possible candidates identified among Murchison (CM2) metal. The preservation of metal grains having condensate signatures within meteorites is rare, because of subsequent oxidation, sulfidization and thermal processing (melting and/or recrystallization) both prior to and after the accretion of chondrites.

Several reports have concluded that metal grains within $\mathrm{CH}$ chondrites and four related meteorites (Bencubbin, Weatherford, QUE94411, and Hammadah al Hamra 237) may have formed by gas-solid condensation from the solar nebula (Newsom and Drake, 1979; Weisberg et al., 1990; 1999; 2000b; Meibom et al., 1999b,c; Petaev et al., 1999). Bencubbin, Weatherford, Hammadah al Hamra 237 (HH237) and QUE94411, paired with QUE94627, are metal-rich meteorites (>50 vol\% Fe,Ni-metal) closely related to the $\mathrm{CH}$ carbonaceous chondrites (Weisberg et al., 1995; 2000a). Like $\mathrm{CH}$ chondrites, these meteorites have isotopically anomalous nitrogen, lack matrix material associated with coarse-grained components (chondrules, CAIs and metal grains); the metal and silicate grains are agglomerated together by a small amount of metal/silicate impact melt (Newsom and Drake, 1979; Weisberg et al., 1998; 1999; Meibom et al., 2000b). Based on the 
observed differences in metal/silicate ratios, oxygen isotope compositions, and chondrule types (e.g., absence of porphyritic chondrules) between these meteorites and $\mathrm{CH}$ chondrites, Weisberg et al. (1998; 2000a) proposed to classify the former as a new carbonaceous chondrite group (CB). However, the significant bulk compositional differences in abundances of refractory lithophile elements between these meteorites (Zipfel et al., 1998; Weisberg et al., 2000a) may compromise the proposed classification. In addition, HH237 and QUE94411 contain abundant chemically zoned Fe,Ni-metal grains, $\mathrm{Ca}, \mathrm{Al}$-rich inclusions, and heavily hydrated matrix lumps composed of phyllosilicates, Cacarbonates, framboidal magnetite, and prismatic Fe,Ni-sulfides (Krot et al., 2000a; 2000b). None of these components has been reported in Bencubbin and Weatherford yet. Although these inconsistencies with the proposed classification could be explained by reheating of Bencubbin, and by poor sampling of this very coarse-grained meteorite (M. Weisberg, private communication), the classification of QUE94411 and HH237 remains unresolved, and in this paper we describe these meteorites as "Bencubbin-like."

A petrologic description of QUE94411 was given by Weisberg et al. (2000a). Weisberg et al. (2000a; 2000b) recognized three classes of metal grain in QUE94411 and HH237: large (mm-sized) aggregates, in which the metal grains have uniform composition and a small amount of sulfide is present; smaller $(100-300 \mu \mathrm{m})$ homogeneous, irregular grains; and radially zoned grains $(100-500 \mu \mathrm{m})$ with high Ni contents in the center and lower Ni toward the grain rims. Nickel and Co, which are more refractory than Fe, are positively correlated with nearly chondritic relative abundances; the more volatile elements $\mathrm{Cr}$ and $\mathrm{P}$ are negatively correlated with $\mathrm{Ni}$, consistent with the calculated condensation sequence for a Fe-rich alloy condensing from a solar gas (Grossman and Olsen, 1974).

This zoning, found in some $\mathrm{CR}, \mathrm{CH}$ and Bencubbin-like chondrite metal grains, has been interpreted as a result of near-equilibrium condensation in the solar nebula (Meibom et al., 1999b; 1999c). The inferred rates of grain growth have been used to constrain cooling rates of 0.2-0.4 K/hr (Meibom et al., 1999c; 2000a), which are lower 
than those interpreted from chondrule formation $(5-1000 \mathrm{~K} / \mathrm{hr}$ ) (Lofgren and Russell, 1986; Radomsky and Hewins, 1990; Lofgren, 1996) yet much higher than those inferred for static cooling of the solar nebula (Podosek and Cassen, 1994). Meibom et al. (2000a) explored the implications of these cooling rates with regard to dynamics of the protoplanetary disk. Petaev et al. (2000) considered disequilibrium models of fractional condensation from gases of non-solar composition to match the $\mathrm{Ni}, \mathrm{Co}$, and $\mathrm{Cr}$ profiles in QUE94411 zoned metal grains.

An important test of these models is the distribution of highly siderophile elements, such as the platinum group elements (PGEs: $\mathrm{Ru}, \mathrm{Rh}, \mathrm{Pd}, \mathrm{Os}, \mathrm{Ir}, \mathrm{Pt}$ ), in the metal grains. The PGEs span a wide range of condensation temperatures (Sylvester et al., 1990); therefore, this suite of elements can provide important insight into volatility-controlled processes such as the condensation of metals from a nebular gas. In this paper we report microanalytical measurements of PGEs and other highly siderophile elements in metal grains in QUE94411. The high spatial resolution $(\sim 30 \mu \mathrm{m})$ and sensitivity afforded by laser ablation ICP-MS allows the microdistribution of siderophile elements to be examined in detail. The siderophile element profiles measured in these grains are compared to models of the condensation process to elucidate possible grain growth processes at high temperatures in the solar nebula. Preliminary results from this study were presented by Campbell et al. (2000).

\section{EXPERIMENTAL}

The thick section QUE94411,6 was X-ray mapped in $\mathrm{Ni} \mathrm{K}_{\alpha}$ with a resolution of $\sim 10 \mu \mathrm{m} /$ pixel using a Cameca SX-50 electron microprobe (EMP) at the University of Hawai'i (Figure 1). Large (>100 $\mu \mathrm{m})$ chemically zoned and unzoned metal grains, identified in Figure 1, were selected for trace element microanalysis by laser ablation inductively coupled plasma mass spectrometry (LA-ICP-MS). Prior to laser ablation the P, $\mathrm{Cr}, \mathrm{Fe}, \mathrm{Co}$, and $\mathrm{Ni}$ compositional profiles of these grains were measured by the Cameca 
SX-50, using a $20 \mathrm{keV}$ accelerating voltage, $30 \mathrm{nA}$ beam current, beam size of $\sim 1-2 \mu \mathrm{m}$ and wavelength dispersive X-ray spectroscopy. For each element, counting times on both peak and background were $60 \mathrm{~s}$. The interference of the $\mathrm{Fe} \mathrm{K}_{\beta}$-line on the $\mathrm{Co} \mathrm{K}_{\alpha}$-line was corrected for in all metal analyses. The section was repolished subsequent to the EMP analyses and prior to the LA-ICP-MS analysis.

A CETAC LSX-200 laser ablation peripheral was used for solid sample introduction into a magnetic sector ICP mass spectrometer, the Finnigan Element ${ }^{\mathrm{TM}}$ (Campbell and Humayun, 1999a; 1999b; 1999c), at the University of Chicago. Each point on the sample was analyzed with 30-pulse laser bursts; the laser-ablated pit produced was approximately $30 \mu \mathrm{m}$ in diameter and $15 \mu \mathrm{m}$ deep. A series of analyses were performed across each grain in $~ 30 \mu \mathrm{m}$ steps. The isotopes monitored were ${ }^{31} \mathrm{P},{ }^{53} \mathrm{Cr},{ }^{57} \mathrm{Fe},{ }^{59} \mathrm{Co}$, ${ }^{60} \mathrm{Ni},{ }^{95} \mathrm{Mo},{ }^{101} \mathrm{Ru},{ }^{103} \mathrm{Rh},{ }^{105} \mathrm{Pd},{ }^{182} \mathrm{~W},{ }^{185} \mathrm{Re},{ }^{192} \mathrm{Os},{ }^{193} \mathrm{Ir},{ }^{195} \mathrm{Pt} ;{ }^{51} \mathrm{~V}$ was added for analysis of the two unzoned grains. The ICP-MS was swept repeatedly, every $0.689 \mathrm{~s}$, across the mass range of interest as the transient pulse of ablated material passed through the instrument. Intensity data were integrated over a $20.7 \mathrm{~s}$ period, during which the signal rapidly increased to a maximum and then decayed toward background levels.

Instrumental sensitivity correction factors for each isotope were determined by measuring signal intensity from the ataxite Hoba, which has known concentrations of the elements of interest (Campbell and Humayun, 1999b; 1999c). The abundances of Ru, Pd, Re, Os, Ir, and Pt in Hoba were determined by isotope dilution ICP-MS, and that of Rh by solution nebulization ICP-MS (Campbell and Humayun, 1999b; 1999c). The Hoba Au value was taken from INAA measurements by Pernicka and Wasson (1987). The W abundance of Hoba was determined by LA-ICP-MS using the Filomena IIA iron as a standard (Sylvester et al., 1990). The P abundance of Hoba was also measured by LAICP-MS, using a schreibersite $\left((\mathrm{Fe}, \mathrm{Ni})_{3} \mathrm{P}\right)$ standard; the phosphide may or may not be an appropriate standard for trace P measurements in a Fe-Ni alloy, and we regard the absolute abundance data for P by LA-ICP-MS as susceptible to systematic error. The corrected 
intensities were converted to elemental abundances by normalization to $[\mathrm{Fe}]+[\mathrm{Co}]+[\mathrm{Ni}]$ $=100 \mathrm{wt} \%$. Precision of the LA-ICP-MS measurements of PGEs was typically $\pm 11 \%$ $(1 \sigma)$, based on repeat measurements of the Hoba standard; counting statistics contributed a significant proportion to the variance, which was typically 7\% for PGEs in QUE94411 metal.

\section{RESULTS}

Electron microprobe analyses across each zoned grain that was selected for analysis by LA-ICP-MS are listed in Table A1. A representative grain profile, measured by electron microprobe, is presented in Figure 2. Note that the nickel concentration reaches a Fe, CInormalized abundance of 2.5 , or $12.5 \mathrm{wt} \%$, at the grain center. Laser ablation ICP-MS data were collected from seven zoned, and two unzoned, Fe-Ni grains in QUE94411 (Table 1). Representative siderophile element profiles across two of the zoned grains and one unzoned grain are shown in Figures 3 to 5.

Comparison of Figures 2 and 3, which both represent the same metal grain, shows satisfactory agreement between the two sets of measurements; both profiles show maximum $\mathrm{Ni}$ and Co normalized abundances of approximately 2.5 and 2.3, respectively, at the center of the grain, and subchondritic abundances of $\mathrm{P}$ and $\mathrm{Cr}$, which have concave upwards profiles. However, in some cases the profiles measured by the two methods differ subtly (Tables A1, 1); there are several reasons for this. First, the planar section of the grains that was probed was different for the EMP and laser ablation, because the sample was repolished between the two sets of measurements, and the depth of penetration of laser ablation $(\sim 15 \mu \mathrm{m})$ is greater than that of the microprobe $(\sim 5 \mu \mathrm{m})$. Second, the profiles were not always measured on the same trace across the grain. Additionally, LA-ICP-MS has coarser spatial resolution than the EMP; therefore it averages over a larger area and cannot identify compositional extrema as well. Finally, there appears to be a systematic offset, (about a factor of 2) in P abundances between the EMP and LA-ICP-MS measurements 
(Tables A1 and 1); this may indicate an inaccurate reference value of $\mathrm{P}$ for our Hoba standard, as discussed above.

As seen in Figures 3 and 4, those siderophiles that are more refractory than Fe display radial gradients in the zoned grains that mimic those of Ni and Co. The PGEs (with the exception of $\mathrm{Pd}$ ) are present at maximum normalized concentrations of two to four times that of CI chondrites; this enrichment diminishes toward the rims of the grains, where the relative abundances are approximately chondritic. Palladium shows no zoning relative to $\mathrm{Fe}$ in the grain interiors. Chromium and $\mathrm{P}$ show profiles complementary to the refractory elements in Figures 3 and 4; $\mathrm{Cr}$ and $\mathrm{P}$ are enriched at the edges of each grain and relatively depleted in the interiors. Molybdenum often shows a maximum in the interior and diminishes toward the rim (Table 1), but is uniformly lower in CI-normalized abundance than the other refractory metals.

The grain in Figure 5, which was identified by electron microprobe as unzoned in $\mathrm{Ni}$ and $\mathrm{Co}$, was found to be unzoned also in PGEs, within error. However, the PGEs, as well as $\mathrm{Ni}$ and $\mathrm{Co}$, are enriched in this grain by factors of 1.2 to 2.2 relative to chondritic proportions.

\section{DISCUSSION}

\subsection{Mechanism of siderophile element fractionation in zoned metal grains}

Earlier analyses of the zoning in metal grains in QUE94411, HH237, and some CH chondrites have concluded that the zoning is the result of a condensation process (Meibom et al., 1999b; 1999c; Weisberg et al., 1999; 2000a; 2000b). We will show in a later section that indeed, the zoning of most PGEs, and particularly the uniform $\mathrm{Pd} / \mathrm{Fe}$ ratio observed across the zoned grains, confirms that the grains formed by a volatility-controlled process such as condensation. First, though, two alternative mechanisms will be evaluated: fractional crystallization from a melt, and reduction of FeO-bearing silicates. 
Fractional crystallization from a metallic melt could not have produced the zoning observed in Figures 2-4. First, Ni is incompatible in partially molten Fe-Ni systems, so it would be expected to show concave (minimum at center) zoning, in contrast to what is observed, if these metal grains were imagined to have crystallized from the inside out. Furthermore, $\mathrm{Ru}, \mathrm{Rh}, \mathrm{Pt}$, Os, and Ir should anticorrelate with Ni because of their strong compatibility in metallic systems (Scott, 1972), but they clearly correlate with Ni instead (Figures 6 and 7). Conversely, $\mathrm{P}$ and $\mathrm{Ni}$, which are expected to correlate during crystallization, anticorrelate in the zoned QUE94411 metal grains. (Scott (1988) made the same argument with regard to $\mathrm{P}$ and Ni in zoned metal in ALH85085.) Palladium exhibits little variation with $\mathrm{Ni}$ in the zoned metal; however, if the observed $\mathrm{Ni}$ variation (greater than a factor of 2 in Figures 2-4) were produced by fractional crystallization from a metallic melt, then fractionation in Pd of at least an order of magnitude would be expected (Figures 6 and 7).

Zanda et al. (1994) have shown that the compositions of chondrule metal may have been controlled by the oxidation state during chondrule formation. Similarly, Lee et al. (1992) proposed that the zoning in metal grains in some CR chondrites is the result of dilution of the rim by $\mathrm{Fe}$ upon $\mathrm{FeO}$ reduction. However, a variation in $\mathrm{f}_{\mathrm{O}_{2}}$ around the QUE94411 metal grains, either by nebular $\mathrm{f}_{\mathrm{O}_{2}}$ changes or parent-body alteration, could not have produced the zoning observed in Figures 2-4. In such a scenario the observed Ni and Co zoning would record a higher $\mathrm{f}_{\mathrm{O}_{2}}$ in the grain core, leading to a loss of Fe and enrichment of $\mathrm{Ni}$ and Co relative to the rim. However, this mechanism would be equally efficient at enhancing the abundances of all of the PGEs, due to their highly siderophile nature. Palladium does not exhibit the anticipated enrichment in the cores (Figures 3 and 4), and therefore this zoning is not a redox-controlled feature. Weisberg et al. (1999) stated that the $\mathrm{Cr}$ profiles are more consistent with a condensation origin than a redox origin of the metal zoning. 
We conclude that the PGE enrichments in the QUE94411 zoned grains were produced by a volatility-controlled process, such as condensation from a gas; this is consistent with the conclusions that Meibom et al. (1999b; 1999c) and Weisberg et al. (1999; 2000a; 2000b) reached based on major- and minor-element studies. The mean compositions of both unzoned grains are also shown (Figure 8) to have enrichment factors that are functions of volatility, with the highest enrichments in the most refractory elements. The core and rim of the zoned grain \#1 exhibit siderophile element abundance patterns similar to the unzoned grains, except with greater and lesser refractory element abundances, respectively (Figure 8). The effects of oxidation on the bulk abundances can be seen, however, particularly in $\mathrm{V}$ and $\mathrm{Cr}$. These two elements are the most easily oxidized of those listed in Figure 8, and their deficiency in the metal grains may reflect their incorporation into oxide and silicate phases instead of the metal. The Mo abundances may also reflect a deficiency due to the oxidation state, although to a lesser degree. The high abundance of $\mathrm{W}$ in unzoned grain \#10 is unexplained; we note that the enhancement does not result from a single $\mathrm{W}$-rich inclusion, as the element is similarly distributed throughout the grain (Table 1).

\subsection{Condensation of a metal alloy from the solar nebula}

The enrichment in refractory PGEs, but not in Pd, in the cores of the zoned metal grains in QUE94411 confirm that these compositions were the result of a volatilitycontrolled process, and not another process that would have fractionated Fe from $\mathrm{Pd}$ in addition to the other noble metals. The fact that the refractory siderophile elements (RSEs) are enriched in the cores, and not at the rims of the grains, indicates that the process was one of condensation and not evaporation. This, in addition to the fact that PGE nuggets were not observed, implies that the metal may have condensed from a gas in which the PGEs were present as the vapor phase. To quantify the process of formation of zoned 
QUE94411 metal, it is necessary to consider the condensation sequence of siderophile elements into a metal.

Equilibrium thermodynamic calculations were used to predict the composition of a condensed metal alloy in equilibrium with a solar gas over a range of temperatures at $10 \mathrm{~Pa}$ $\left(10^{-4}\right.$ bar). The calculations were carried out following the procedure of Palme and Wlotzka (1976) and Fegley and Palme (1985). For each element M the equation

$$
P_{M}(\text { alloy })=P_{M}(\text { nebula })
$$

is considered. $\mathrm{P}_{\mathrm{M}}$ (nebula) is the partial pressure of an element in the solar nebula, and $\mathrm{P}_{\mathrm{M}}($ alloy $)$ is the partial pressure of the element over the alloy:

$$
P_{M}(\text { alloy })=a_{M} P_{M}^{0}
$$

where $\mathrm{a}_{\mathrm{M}}$ is the activity of $\mathrm{M}$ in the alloy and $\mathrm{P}^{0}{ }_{\mathrm{M}}$ is the vapor pressure of pure $\mathrm{M}$. Vapor pressure data for each element (Hultgren et al., 1973a) over the range 1300-2000 K are fitted to an equation of the form

$$
\log \left(P_{M}^{0}\right)=-\frac{A}{T}+B
$$

to allow interpolation to each temperature of interest. The coefficients A and B used here are listed in Table 2. The partial pressure of oxide gases were calculated from

$$
P_{M_{x} O_{y}}=a_{M} P_{O_{2}}{ }^{y / 2} K_{M_{x} O_{y}}
$$

where the equilibrium constants $\mathrm{K}_{\mathrm{MxOy}}$ were taken from the JANAF tables (Chase, 1998), and the $\mathrm{P}_{\mathrm{O}_{2}}$ was adopted from Ebel and Grossman (2000). Most of the elements

considered here are highly siderophile and can be assumed, in a gas of solar composition, to exist exclusively as monatomic species when in the gaseous phase (Fegley and Palme, 1985; Sylvester et al., 1990). Gaseous oxides of only V, Fe, Mo, and W were considered, and the species included were: $\mathrm{VO}, \mathrm{VO}_{2}, \mathrm{FeO}, \mathrm{MoO}, \mathrm{MoO}_{2}, \mathrm{MoO}_{3}, \mathrm{WO}, \mathrm{WO}_{2}, \mathrm{WO}_{3}$, $\mathrm{W}_{2} \mathrm{O}_{6}, \mathrm{~W}_{3} \mathrm{O}_{8}, \mathrm{~W}_{3} \mathrm{O}_{9}$, and $\mathrm{W}_{4} \mathrm{O}_{12}$. The activity $\mathrm{a}_{\mathrm{M}}$ is described by

$$
a_{M}=\gamma_{M} \frac{\alpha_{M} C(M)}{\sum \alpha_{i} C(i)}
$$

where $\gamma_{M}$ is the activity coefficient of $M$ in the alloy, the $\alpha_{i}^{\prime}$ s are the fractions of each element $i$ condensed into the alloy, and $\mathrm{C}(i)$ is the cosmochemical abundance of element $i$. 
The activity coefficients used in the present calculations are listed in Table 2. Values for V, Co, Ni, and Pd were taken from Hultgren et al. (1973b), and it was assumed that their variations with temperature and composition were negligible over the narrow ranges considered here. Fegley and Palme (1985) and Palme and Wlotzka (1976) briefly discuss the available activity coefficient data for platinum group elements. Although the existing data are scarce, they suggest that non-ideality effects for most highly siderophile elements may be small and do not justify the use of coefficients different from unity. Furthermore, under equilibrium conditions the most refractory siderophiles condense entirely before $\mathrm{Fe}$ condenses in any significant fraction; therefore their activity coefficients have minimal effect on the calculations in the region where Fe-bearing alloys are condensing. The values of $\gamma$ for $\mathrm{V}, \mathrm{Ni}, \mathrm{Co}$, and $\mathrm{Pd}$, in contrast, have greater impact on the calculated composition of Fe-rich condensates.

The partial pressure of an element in the solar nebula is described by

$$
P_{M}(\text { nebula })=\left(1-\alpha_{M}\right)\left(\frac{P_{M}}{P_{\Sigma M}}\right)\left(\frac{C(M)}{C\left(H_{2}\right)}\right) P_{t o t}
$$

where $\mathrm{P}_{\text {tot }}$, the total pressure of the solar nebula, is assumed equal to the partial pressure of $\mathrm{H}_{2}$ and

$$
P_{\Sigma M}=\sum x P_{M_{x} O_{y}}
$$

is the pressure of all gaseous species $\mathrm{M}_{\mathrm{x}} \mathrm{O}_{\mathrm{y}}$ containing element $\mathrm{M}$.

Combining equations (1) - (3), (5), and (6), $\alpha_{M}$ can be expressed as

$$
\alpha_{M}=\left[1+10^{\left(-\frac{A}{T}+B\right)}\left(\frac{P_{\Sigma M}}{P_{M}}\right)\left(\frac{C\left(H_{2}\right)}{P_{t o t} \sum \alpha_{i} C(i)}\right)\right]^{-1}
$$

Equations (4), (7), and (8) were solved iteratively for the $\alpha_{i}$ 's, and alloy compositions were calculated from $\alpha_{i}, \mathrm{C}(i)$, and the mean atomic weights of the elements.

The calculated condensation curves for siderophile elements condensing into a single alloy from a gas of solar composition at $10 \mathrm{~Pa}$ are presented in Figure 9. These results compare well with those of Fegley and Palme (1985) and Sylvester et al. (1990). As shown, all of the PGEs except Pd are completely condensed at equilibrium prior to the 
condensation of even $10 \%$ of Fe. Nickel and Co are slightly more refractory than Fe, and Pd has a volatility nearly identical to that of Fe.

The calculations, spanning temperatures of $1360 \mathrm{~K}$ ( $\mathrm{T}_{\mathrm{c}}$ of high Ni cores) to $1260 \mathrm{~K}$ ( $\mathrm{T}_{\mathrm{c}}$ of low Ni rims), are compared to the LA-ICP-MS data from two separate zoned grains in Figures 6 and 7. As seen in these figures, there is broad agreement between the measured and calculated PGE vs. Ni composition trends. Palladium varies only slightly with Ni content, consistent with the data from the grains in Figures 3 and 4; this reflects the fact that Pd has a volatility similar to that of Fe. The other PGEs vary by more than a factor of two over this temperature range; the concordance between the LA-ICP-MS data and the model is very strong for all refractory PGEs in Figure 7. As seen in Figure 6, the calculated and observed PGE vs. Ni curves from the grain approximately match, although there is a small, systematic discrepancy for Os, Ir and Pt; the measured values of these elements are lower than the calculated abundances by $20-30 \%$ in this grain. Of the seven zoned grains studied in QUE94411, the grain in Figure 6 exhibits the highest levels of depletion of Os, Ir, and Pt; several grains, such as the one in Figure 7, show no such depletions at all. This mismatch may reflect varying pressure conditions in which different grains condensed. The effect of nebular pressure on the calculations is demonstrated in Figure 10; lower PGE abundances at a given $\mathrm{Ni}$ concentration are expected at lower $\mathrm{P}_{\text {tot }}$. Alternatively, the reduced refractory PGE abundances may reflect condensation of these grains from a refractorydepleted gas, from which solids sequestering PGEs had been previously removed.

Previous treatments of the zoning in $\mathrm{Ni}, \mathrm{Co}$, and $\mathrm{Cr}$ interpreted the data in terms of a model involving fractional condensation, in which each successive shell of a growing grain was deposited with the composition of the metal alloy in equilibrium with the surrounding fractionated gas (Meibom et al., 1999b; 1999c; Petaev et al., 1999). However, as Figure 9 indicates, the PGEs are so refractory in a hot nebular gas that the earliestcondensing Fe-Ni alloy would consume practically the entire refractory PGE budget; there would be no refractory PGEs available for subsequent condensation with $\mathrm{Fe}-\mathrm{Ni}$ while 
depositing the outer shells of a growing grain in this model. The expected outcome of an equilibrium fractional condensation model, shown in Figure 11, would be characterized by PGE profiles that exhibit a sharp spike in concentration at the center of the grain, with essentially no refractory PGEs elsewhere. Note that the calculated Ni and Co profiles, which have more gradual gradients from core to rim, still decrease to zero abundance toward the rim of the modelled grain due to high-temperature sequestering into the cores, in contrast to the observed gradients which have minimum concentrations that are chondritic or slightly below chondritic (Weisberg et al., 1999; Meibom et al., 1999b; 1999c).

It is apparent that any fractional condensation model proposed to generate the zoned grains in QUE94411 must account for three features of the refractory siderophile profiles: 1) enrichment of refractory siderophiles and depletion of volatile siderophiles in the grain cores; 2) a core-to-rim abundance decrease to nearly chondritic proportions at the rim, as seen in Figures 3 and 4; and 3) concentration of highly refractory siderophiles ( $\mathrm{Ru}, \mathrm{Rh}$, Os, Ir, Pt) into the grain cores to a much lower extent than predicted by the equilibrium condensation sequence, i.e., the lack of a PGE spike at the grain center. We explore two alternative models to explain the PGE abundances in the zoned metal grains: 1) grain growth by condensation in a nebular gas that is cooling rapidly with respect to the rate of metal deposition onto grain surfaces, and therefore remains supersaturated in PGEs; 2) condensation at high temperatures to establish high refractory PGE concentrations in the grain cores, and subsequent condensation of PGE-depleted metal, followed by a diffusion process to generate the observed zoning pattern. Each of these hypotheses will be considered below.

\subsection{Establishment of zoning by grain growth in a cooling, supersaturated gas}

Meibom et al. (1999c; 2000a) calculated the rate of grain growth from a gas of solar composition, for the case in which condensation of new metal onto the surface is controlled 
by gas kinetics. They found that the cooling rate of a solar gas at $10 \mathrm{~Pa}$ should be $0.2 \mathrm{~K} / \mathrm{hr}$, based upon the size of the grain and a condensation interval of $100 \mathrm{~K}$. It is conceivable that at this high cooling rate, homogeneous nucleation and growth of Fe-Ni alloy may be too slow for equilibrium to be maintained between the solid grains and the surrounding gas, and that as a result the gas would remain supersaturated in refractory elements. (In this scenario the highly refractory siderophile elements are inhibited from nucleation at higher $\mathrm{T}$ because they are highly rarified in the nebula; with the relatively rapid cooling rate considered here they remain available in the gas for condensation into the Fe-Ni alloy.)

In this section such a model is explored. We postulate that nucleation was suppressed in the region in which the zoned grains formed, because of the high cooling rate and the low gas density. Upon nucleation, which is here simplified as the instantaneous creation of a fixed number of nuclei, the metal grains grow at a rate constrained by gas kinetics, and the composition of the deposited metal varies as a result of the changing temperature. If the density of nuclei is low, the fraction of available metal that condenses in a rapidly cooling $(0.2 \mathrm{~K} / \mathrm{hr})$ region of the nebula is negligible and the gas composition is effectively unfractionated. In this way the composition trajectory of the condensing metal may follow the calculated equilibrium path, as in Figure 7.

The rate at which nucleation occurred in the solar nebula can in principle be modelled using classical nucleation theory (Feder et al., 1966). The nucleation rate of an element condensing from a monomer gas is given by

$$
J_{n}=\beta \Omega\left(\frac{2 \gamma}{\pi m}\right)^{\frac{1}{2}} C^{2} \exp \left\{-\frac{4 \sigma^{3}}{27(\ln S)^{2}}\right\}
$$

where $J_{n}$ is the number of nuclei formed per unit time per unit volume, $\beta$ is the sticking coefficient, $\Omega$ is the volume of an element monomer, $\gamma$ is the surface energy of the condensate, $\mathrm{m}$ is the monomer mass, $\mathrm{C}$ is the concentration of monomers in the gas, $\sigma=$ $4 \pi \gamma \mathrm{a}_{0}{ }^{2} / \mathrm{kT}, \mathrm{a}_{0}$ is the monomer radius, and $\mathrm{S}$ is the supersaturation ratio $\mathrm{P} / \mathrm{P}_{\mathrm{eq}}$ (partial pressure in the supersaturated gas to the equilibrium partial pressure). Yamamoto and 
Hasegawa (1977) calculated, for representative nebular conditions, that the nucleation rate of $\mathrm{Fe}$ is low enough that its effective condensation temperature would be lowered by about $200 \mathrm{~K}$. Our calculations, with a nebular pressure of $10 \mathrm{~Pa}$ and a cooling rate of $0.2 \mathrm{~K} / \mathrm{hr}$, also indicate that Fe nucleation will be suppressed below the equilibrium $\mathrm{T}_{\mathrm{c}}$ of $1363 \mathrm{~K}$, and that the nucleus density will reach $0.01 \mathrm{~m}^{-3}$ at $1173 \mathrm{~K}$; this result is broadly in agreement with that of Yamamoto and Hasegawa (1977). The fact that it is an alloy condensing, instead of pure Fe, will raise the nucleation rate, and effective condensation temperature, by an uncertain amount due to the supersaturation of more refractory metals at higher temperature. The conclusion remains, however, that at a sufficiently high cooling rate, nucleation of alloys from a solar gas is kinetically inhibited due to the low concentrations and consequently low degrees of supersaturation of metal near the equilibrium condensation point. Therefore, supersaturation of the nebula in alloy components is a plausible basis upon which to model formation of the zoned metal in QUE94411.

This scenario was modelled quantitatively, the results of which are depicted in Figure 12. In this model, we set a fixed number of nuclei upon which the surrounding gas of (initially) solar composition deposits successive layers of Fe-Ni alloy as the gas cools. The composition of the condensing alloy shell was determined by equilibrium with the gas, and the shell thickness was calculated using kinetic theory of gases, given the time interval available as determined by the specified cooling rate. At each temperature step $(\Delta \mathrm{T}=5 \mathrm{~K})$ the gas composition was modified by the mass that condensed over that time interval; this mass was derived from the calculated shell thickness and the chosen number of nuclei. The resulting siderophile element profiles in Figure 12 have several characteristics in common with the data from zoned QUE94411 metal grains: 1) the maximum refractory PGE concentration, represented by Ir in Figure 12, is about 3-4 times chondritic, and the Ni and Co concentrations are about 2.5 times chondritic, in the core; 2 ) all siderophile element concentrations trend toward chondritic relative abundances as the grain rim is approached; and 3) the PGE vs. Ni composition trajectory defined along the radius of the grain follows 
that of the equilibrium condensation path. Therefore, this model satisfies the observed composition trends in zoned QUE94411 grains in important aspects in which the equilibrium fractional condensation model (Figure 11) failed.

A difficulty with the supersaturated gas model is the shape of the calculated profiles for the siderophile elements. In Figure 12 it is clearly seen that profiles of both the PGEs and the minor elements $\mathrm{Ni}$ and $\mathrm{Co}$ are predicted to exhibit cusps of abundance maxima in the center of the grains, with concave upward trends toward the grain rim. It is evident from the zoning profiles of Ni, Co, and refractory PGEs in QUE94411 metal grains, which exhibit convex-upward profiles (Figures 2, 3, and 4), that this is not the case. No simple adjustment of the fixed input parameters in the saturated gas model will produce convex composition profiles like those in Figures 2, 3, and 4. The reason for the concavity is that the grain grows increasingly rapidly as the nebula cools, causing each successive growth layer, with lower refractory siderophile content, to be thicker than the previous ones. A potential improvement to this model would be to include a time- and temperature-dependent nucleation rate, such as that described in the definition of $J_{n}$ above, rather than the assumption of a fixed number of nuclei employed here. This more realistic scenario would allow the number of nuclei to increase during cooling, thereby reducing the thickness of successive growth layers and conceivably producing the convex profiles that are observed.

The model shown in Figure 12 can accomodate a wide range in each of the input parameters. The total pressure used to model grain growth in Figure 12, $10 \mathrm{~Pa}$, was taken from Meibom et al. (1999c). They adopted this value for the nebular pressure based on the silicon content of zoned metal grains in $\mathrm{CH}$ chondrites. It is possible that the grains in QUE94411 formed at different pressures, or even at a range of pressures; the effect of nebular pressure on the model is considered below. Once $\mathrm{P}_{\text {tot }}$ is chosen, the trajectory of composition vs. temperature for equilibrium condensation is defined by the thermodynamic properties of the system (Grossman, 1972). For the dynamic grain growth model, an initial temperature $\mathrm{T}_{0}$ must be defined at which nucleation is specified to occur. We chose $\mathrm{T}_{0}=$ 
$1355 \mathrm{~K}$ in Figure 12; this sets the composition of the grain core to approximately match the peak abundances observed in Figure 3. A higher choice of $\mathrm{T}_{0}$ would produce greater refractory abundances in the core; a lower $\mathrm{T}_{0}$ would produce lower core abundances. The growth rate is constrained by the pressure and temperature via

$$
\frac{d r}{d t}=(1-\alpha) \beta \frac{P_{H_{2}}}{\rho} \frac{A(F e)}{A\left(H_{2}\right)} \sqrt{\frac{M}{2 \pi R T}}
$$

where $r$ is the radius of the growing grain, $\alpha$ is the fraction condensed, $\beta$ is a sticking coefficient (here assumed to be 1), $\rho$ is the grain's density, A is solar abundance, and $\mathrm{M}$ is the grain's mean atomic mass. The number density of nuclei, $\mathrm{n}_{\mathrm{n}}$, and the cooling rate are chosen such that $\alpha$ is negligible; this reflects the high degree of supersaturation that is the principal assumption that is made to generate nearly chondritic abundances at the grain rims. In Figure $12 \mathrm{n}_{\mathrm{n}}$ is $0.01 \mathrm{~m}^{-3}$. Reducing this density has negligible effect on the calculation because the gas is already highly supersaturated. Raising $\mathrm{n}_{\mathrm{n}}$ above $\sim 0.03 \mathrm{~m}^{-3}$, holding other parameters fixed, allows the degree of supersaturation to lessen. This has two consequences: 1) the grain size becomes smaller because the same mass of condensing material is distributed over more grains, and 2) the abundances of RSEs become slightly subchondritic at the rims due to sequestering in grain cores. The cooling rate chosen for Figure 12 is $0.2 \mathrm{~K} / \mathrm{hr}$; this was adopted from Meibom et al. (1999c) and produces a grain of about $100 \mu \mathrm{m}$ radius -- typical of those observed in QUE94411. Raising the cooling rate allows less time for grain growth, yielding grains of smaller radii at the end of the $100 \mathrm{~K}$ temperature interval considered; conversely, lowering the cooling rate yields grains of larger radii. Slowing the cooling rate sufficiently will also have the effect of reducing supersaturation; if the cooling rate is slow enough, of course, this model becomes indistinguishable from the equilibrium fractional condensation model in Figure 11. Finally, the nebular pressure controls the rate of deposition. Supersaturation can be imposed at any pressure, however, by adjusting either the cooling rate or the number density of nuclei to compensate for high partial pressures. 
Petaev et al. (2000) also explored a fractional condensation model to generate $\mathrm{Ni}$, $\mathrm{Co}$, and $\mathrm{Cr}$ composition profiles like those presented here. They did not examine the issue of highly refractory siderophile elements such as the PGEs, and therefore included no mechanism in their calculations for keeping the PGEs available in the gas reservoir for condensation into the grain rims. Petaev et al. (2000) calculate that growth of the zoned metal grains initiated when $>50 \%$ of the Ni had already condensed; at this stage $100 \%$ of refractory PGEs would have condensed as well. Consequently the condensation models of Petaev et al. (2000) predict either an absence of PGEs in the zoned grains, or a PGE composition spike in the grain cores (Figure 11); neither of these is compatible with the PGE abundances presented in this paper.

\subsection{Establishment of zoning by diffusion}

Previous studies of zoned metal grains in CR and Bencubbin-like chondrites have emphasized a condensate origin to explain the compositional gradient in these objects (Meibom et al., 1999a; 1999b; 1999c; 2000a; 2000b; Petaev et al., 1999, 2000; Weisberg et al., 1999; 2000b). It may also be productive to consider an alternative model, in which the internal composition of a condensate grain is modified by high-temperature diffusion either during grain formation or at a later stage (Campbell et al., 2000; Weisberg et al., $2000 \mathrm{~b})$. Even if diffusion was not the dominant process for zoning the metal grains, it may have played an important minor role by blurring condensate features.

One of the primary lines of evidence that have been used to support the condensation models has been interelement correlations of the sort shown in Figures 6 and 7; the agreement between measurements and calculated condensation trajectories is strongly suggestive, and indeed data like these have even been used to constrain the modelled conditions of condensation (Meibom et al., 1999bc; 2000a; Petaev et al., 2000). However, the observed linear siderophile element $v s$. Ni trends might also be interpreted as a mixing line between two components that are interdiffusing: a high-temperature condensate that is 
refractory-rich and volatile-poor, and a surrounding reservoir of nearly chondritic composition. The convex-upward RSE profiles (Figure 2) may also reflect the process of diffusion.

The initial composition of the grains, in this model, can be assumed to be that of the grain cores, where the refractory elements reach maxima. It is conceivable that the initial grain compositions were at even higher refractory siderophile compositions than those measured, as a consequence of the sectioning of the sample or of the diffusive zone reaching the grain center and reducing the abundance of refractories there. In either case it is expected that the true initial composition of the grains would lie along an extension of the approximately linear trends defined in Figures 6 and 7. It is important to emphasize that even in the diffusion-based model for metal zoning, the initial metal composition indicates a volatility-based origin such as condensation from the solar nebula. As explained above, no other physical process can explain the enrichments in refractory siderophiles, depletions in volatile siderophiles, and chondritic proportions of $\mathrm{Pd}$, which has similar volatility to $\mathrm{Fe}$.

The composition of the reservoir into which the refractory siderophiles may have diffused is less obvious. The nature of the parent body of QUE94411, and the situation of the meteorite components within this parent body, are poorly constrained. Therefore, although we cannot exclude a parent body process for the metal zoning, we consider instead a hypothesis in which the zoning in the metal grains was formed by a diffusive process while the grains were still free in the solar nebula.

Consider a high-temperature condensate grain surrounded by a cooling nebula. As a shell of lower-temperature alloy is deposited onto the surface of the growing grain, diffusion occurs between the high-temperature core and the low-temperature shell. In the simplest, two-shell model, a high-temperature core would be encased in a larger shell of approximately chondritic abundances, and diffusion would then proceed between the two regions of the grain. Initially the rim composition would remain nearly unchanged, because of the large volume difference between the two regions of the grain (there is necessarily 
much more low-temperature alloy than there is high-temperature alloy, as described above and illustrated in Figure 9). The core composition would depend on the degree to which the inner and outer portions of the grain were equilibrated, but would represent an intermediate between the initial high- and low-temperature alloy compositions. More complex models of this sort would involve multiple growth layers from a cooling nebula; at the limit of continuous growth while cooling, this model bears strong similarities with the model considered above, of fractional condensation from supersaturated gas, except here the cooling rate is considered to be slow enough to allow diffusion between interior and exterior zones of the grain.

The temperatures and timescales on which intragrain diffusion would occur depend on the conditions of condensation as well as the diffusion coefficients of the siderophile elements in Fe-Ni alloys. The Fe-Ni interdiffusion coefficient under conditions of interest here was measured by Goldstein et al. (1965) as

$$
D=e^{1.15+0.0519 C_{N i}+\frac{5.84 C_{N i}-38400}{T}}
$$

where $\mathrm{D}$ is in $\mathrm{cm}^{2} \mathrm{~s}^{-1}, \mathrm{C}_{\mathrm{Ni}}$ is in atomic $\%$, and $\mathrm{T}$ is in Kelvin. For representative nebular conditions of $10 \mathrm{~Pa}$ and $1360 \mathrm{~K}$, and a $\mathrm{Ni}$ abundance of $13 \mathrm{wt} \%$, the diffusion coefficient is on the order of $3 \times 10^{-12} \mathrm{~cm}^{2} \mathrm{~s}^{-1}$. This parameter is, of course, highly dependent on temperature; D changes by about an order of magnitude for each change in T of $100 \mathrm{~K}$. Lowering the Ni content to $6 \mathrm{wt} \%$ only decreases the diffusion coefficient by a factor of 1.5. Representative timescales of diffusion are compared to the minimum timescale of condensing a $400 \mu \mathrm{m}$ grain under various nebular pressures in Table 3. Both grain growth and diffusion become more rapid at higher $\mathrm{P}, \mathrm{T}$ conditions of condensation, but grain growth outpaces diffusion for condensation from a solar gas above $\sim 1 \mathrm{~Pa}$. This is a necessary requirement for preservation of the zoned profiles documented in Figures 2, 3, and 4. Increasing the dust/gas ratio in the nebula, as suggested by Petaev et al. (2000), would further enhance the grain growth rate (Equation 10). 
Kamacite exsolution from the zoned taenite grains has not been observed in QUE94411 (Weisberg et al., 2000b). Therefore, the cooling rate through the $\alpha+\gamma$ phase region (between $\sim 1050 \mathrm{~K}$ and $\sim 650 \mathrm{~K}$ for these compositions (Goldstein and Short, 1967)) must have been rapid enough to preclude kamacite formation during cooling of these grains, and subsequent thermal metamorphism was minimal (Meibom et al., 1999c; Weisberg et al., 2000b). However, this phase transition in Fe-Ni alloys places no constraint on the thermal history of the QUE94411 zoned metal above $\sim 1050 \mathrm{~K}$.

The similarity in M-shaped profiles between PGEs and Ni in taenite lamellae in octahedrite iron meteorites (Campbell and Humayun, 1999b; Hsu et al., 2000) suggest that the diffusion rates of PGEs and Ni are of comparable order of magnitude, at least over the temperature interval in which the Widmanstatten pattern forms, approximately $1050 \mathrm{~K}$ to $650 \mathrm{~K}$. Consequently, we assume in this discussion that the PGEs have diffusion rates identical to those of $\mathrm{Ni}$.

There is a radial gradient in $\mathrm{P}$ abundance in QUE94411 zoned metal (Figures 3 and 4). Phosphorus is known to diffuse more quickly, by approximately two orders of magnitude, than Ni in ferrous alloys (Heyward and Goldstein, 1973). This difference in diffusion coefficients requires that the $\mathrm{P}$ and Ni profiles could not both be produced by diffusion at the same time. During the time necessary for Ni to diffuse from the core to the rim of a $200 \mu \mathrm{m}$ metal grain, P would diffuse so extensively that its abundance would be nearly uniform in the metal. Therefore, either the rates of grain growth and cooling were so fast, and subsequent temperatures held so low, that diffusion of P did not occur (and, by extension, not of $\mathrm{Ni}$ or the PGEs either), or the observed $\mathrm{P}$ profile is a signature from a later event at a temperature low enough that the highly siderophile elements could not diffuse, but $\mathrm{P}$ could. This scenario is, in principle, possible; the observed diffusion of $\mathrm{P}$ by $200 \mu \mathrm{m}$ (Figure 3) would, assuming a ratio of $\mathrm{D}_{\mathrm{P}} / \mathrm{D}_{\mathrm{Ni}}$ of 100 , correspond with diffusion of Ni by only $20 \mu \mathrm{m}$, which may not be noticeable. Therefore, the observed concentration 
gradients in $\mathrm{P}$ cannot be used to exclude a diffusional mechanism for establishing the $\mathrm{Ni}$ and PGE profiles in QUE94411 zoned metal.

The preservation of zoning in the metal places important constraints on the timescale of formation of these grains. As discussed above, and by Meibom et al. (1999), these grains require at least 20-40 days to grow to their present size, assuming a total nebular pressure of $10 \mathrm{~Pa}$. An upper limit on the timescale of grain growth is reached in the case in which the zoning is produced by diffusion. At a temperature of $1260 \mathrm{~K}$, appropriate to condensation of metal having chondritic proportions of RSEs at $10 \mathrm{~Pa}$, the time interval of Ni diffusion across the $200 \mu \mathrm{m}$ radius is $\sim 50$ years. Insight into the processes affecting these grains at lower temperatures, after the condensation of Fe, would allow tighter constraints to be placed on the timescales and mechanisms of formation of the zoned metal grains in QUE94411 and related meteorites. A study of the distribution of moderately volatile siderophile elements in these samples would be useful for this purpose.

\section{CONCLUSIONS}

The Ni and Co gradients in QUE94411 zoned metal grains are mimicked by other refractory siderophile elements such as the PGEs. By measuring a greater number of siderophiles, covering a wider range of volatilities, it was confirmed that the refractory siderophile enrichment in these grains is the result of a volatility-controlled process, e.g. high-temperature condensation. However, simple modelling of grain growth via equilibrium fractional condensation in a cooling solar nebula revealed that the PGE zoning in these grains could not have formed during such a process; the entire budget of highly refractory siderophiles would have been concentrated in the cores of the grains, in contrast to the more even distributions that are observed.

Two models were presented to explain the observed siderophile element zoning: fractional condensation in a rapidly cooling, supersaturated nebula, that first nucleates a metal alloy composed of $\mathrm{Fe}-\mathrm{Ni}$; and diffusion between a high-temperature condensate core, 
enriched in refractory siderophiles, and an outer shell of nearly chondritic siderophile abundances. These two mechanisms are not mutually exclusive, but should instead be viewed as members of a suite of models, in which an initially PGE-rich core diffusively equilibrates to a greater or lesser extent with a series of encasing condensate shells, which may represent a single lower-T event or a gradual deposition of metal.

The data currently available on QUE94411 do not allow one to resolve the relative importance of diffusion or fractional condensation in causing these zonations. It is possible that careful study of the diffusion rates of various siderophile elements, such as the PGEs, would establish whether the observed distributions are consistent with diffusion of this suite of elements through a Fe-Ni alloy. Such PGE diffusion data are greatly required to evaluate the kinetics of PGE distribution in meteoritic metal. A further approach would be to examine the distribution of more volatile siderophiles such as $\mathrm{Cu}, \mathrm{Ga}$, and $\mathrm{Ge}$. Fractional condensation in a rapidly cooling, supersaturated gas would produce steep increases in these volatile elements toward the rims of the grain, with greatly depleted concentrations in the grain interiors. If the zoning were primarily a diffusional effect, then these elements would exhibit more gradual zoning patterns, similar to those of $\mathrm{Cr}$ and $\mathrm{P}$ (assuming again that their diffusion rates are similar to those of $\mathrm{Ni}$ ).

Resolution between the models described is important to better decipher the nebular environment in which formation of these metal grains occurred. One limiting case involves the familiar scenario of a high-temperature condensate grain gradually equilibrating with the surrounding nebula. The other extreme, of condensation from a rapidly cooling, supersaturated gas, requires novel interpretations of the mechanics of the early solar nebula (Meibom et al., 2000a).

Acknowledgments -Section QUE94411,6 was generously provided by the Meteorite Working Group. Discussions with L. Grossman, D. Ebel, and B. Zanda were helpful. Comments on the original manuscript, provided by H. Connolly, G. Kurat, M. Weisberg, 
L. Grossman, and F. Richter, are appreciated. A. M. is grateful for support from the Danish Science Research Council. This work was supported by NSF EAR-9601478 and NASA NAG 5-9800 to M. H. and NASA NAG 5-4212 to K. K. 


\section{REFERENCES}

Anders E. and Grevesse N. (1989) Abundances of the elements: Meteoritic and solar. Geochim. Cosmochim. Acta 53, 197-214.

Boss A. P. (1993) Evolution of the solar nebula. II. Thermal structure during nebula formation. Astrophys. J. 417, 351-367.

Campbell A. J. and Humayun M. (1999a) Microanalysis of siderophile elements in Fremdlinge using laser ablation ICP-MS. Lunar Planet. Sci. Conf. XXX, \#1609.

Campbell A. J. and Humayun M. (1999b) Platinum group element microanalysis of iron meteorites. In preparation.

Campbell A. J. and Humayun M. (1999c) Trace element microanalysis in iron meteorites by laser ablation ICPMS. Anal. Chem. 71, 939-946.

Campbell A. J., Humayun M., Meibom A., and Krot A. N. (2000) Platinum group element distributions in bencubbinite metal grains. Lunar Planet. Sci. Conf. XXXI, \#1490.

Cassen P. (1994) Utilitarian models of the primitive solar nebula. Icarus 112, 45-429.

Chase, M. W. Jr. (1998) NIST-JANAF Thermochemical Tables, 4th ed. J. Phys. Chem. Ref. Data Monograph No. 9, American Institute of Physics.

Ebel D. and Grossman L. (2000) Condensation in dust-enriched systems. Geochim. Cosmochim. Acta 64, 339-366.

Feder J., Russell K. C., Lothe J., and Pound G. M. (1966) Homogeneous nucleation and growth of droplets in vapours. Adv. in Phys. 15, 111-178.

Fegley B. Jr. and Palme H. (1985) Evidence for oxidizing conditions in the solar nebula from Mo and W depletions in refractory inclusions in carbonaceous chondrites. Earth Planet. Sci. Lett. 72, 311-326.

Goldstein J. I. and Short J. M. (1967) Cooling rates of 27 iron and stony-iron meteorites. Geochim. Cosmochim. Acta 31, 1001-1023. 
Goldstein J. I., Hanneman R. E., and Ogilvie R. E. (1965) Diffusion in the Fe-Ni system at $1 \mathrm{~atm}$ and $40 \mathrm{kbar}$ pressure. Trans. Metall. Soc. AIME 233, 812-820.

Grossman L. (1972) Condensation in the primitive solar nebula. Geochim. Cosmochim. Acta 36, 597-619.

Grossman L. (1980) Refractory inclusions in the Allende meteorite. Ann. Rev. Earth Plan. Sci. 8, 559-608.

Grossman L. and Larimer J. W. (1974) Early chemical history of the solar system. Rev. Geophys. Space Phys. 12, 71-101.

Grossman L. and Olsen E. (1974) Origin of the high-temperature fraction of C2 chondrites. Geochim. Cosmochim. Acta 38, 173-187.

Heyward T. R. and Goldstein J. I. (1973) Ternary diffusion in the $\alpha$ and $\gamma$ phases of the Fe-Ni-P system. Metall. Trans. 4, 2335-2342.

Hsu W., Huss G. R., and Wasserburg G. J. (2000) Ion probe measurements of Os, Ir, Pt, and $\mathrm{Au}$ in individual phases of iron meteorites. Geochim. Cosmochim. Acta 64, 11331147.

Hultgren R., Desai P. D., Hawkins D. T., Gleiser M., Kelley K. K., and Wagman D. D. (1973a) Selected Values of the Thermodynamic Properties of the Elements, American Society for Metals.

Hultgren R., Desai P. D., Hawkins D. T., Gleiser M., and Kelley K. K. (1973b) Selected Values of the Thermodynamic Properties of Binary Alloys, American Society for Metals.

Humayun M. and Cassen P. (2000) Processes determining the volatile abundances of the meteorites and terrestrial planets. In Origin of the Earth and Moon (eds. K. Righter and R. M. Canup). Univ. Arizona Press. pp. 3-23.

Krot A. N., McKeegan K. D., Zipfel J., Weisberg M. K., Meibom A., Russell S. S., and Keil K. (2000a) Refractory inclusions and Al-rich chondrules in Bencubbin/CH-like 
carbonaceous chondrites Hammadah al Hamra 237 and QUE94411. Lunar Planet. Sci. Conf. XXXI, \#1448.

Krot A. N., Meibom A., Russell S. S., Young E., Alexander C. M., McKeegan K. D., Lofgren G., Cuzzi J., Zipfel J., and Keil K. (2000b) Chondrules of the very first generation in Bencubbin/CH-like meteorites QUE94411 and Hammadah al Hamra 237: Condensation origin at high ambient nebular temperatures. Lunar Planet. Sci. Conf. XXXI, \#1499.

Lee M. S., Rubin A. E., and Wasson J. T. (1992) Origin of metallic Fe-Ni in Renazzo and related chondrites. Geochim. Cosmochim. Acta 56, 2521-2523.

Lofgren G. E. (1996) A dynamic crystallization model for chondrule melts. In Chondrules and the Protoplanetary Disk (eds. R. E. Hewins, R. H. Jones, and E. R. D. Scott), pp. 187-196. Cambridge Univ. Press.

Lofgren G. and Russell W. J. (1986) Dynamic crystallization of chondrule melts of porphyritic and radial pyroxene composition. Geochim. Cosmochim. Acta 50, 17151726.

Meibom A., Hicks T., Scott E. R. D., Norman M., Krot A. N., and Keil K. (1999a) Search for nebular fractionation of moderately volatile siderophile elements in metal grains in CR-clan meteorites. Lunar Planet. Sci. Conf. XXX, \#1419.

Meibom A., Petaev M., Krot A. N., Hicks T., Scott E. R. D., and Keil K. (1999b) Condensation origin of some metal grains in $\mathrm{CH}$ chondrites: implications for the formation of metal in the CR-clan. Lunar Planet. Sci. Conf. XXX, \#1411.

Meibom A., Petaev M. I., Krot A. N., Wood J. A., and Keil K. (1999c) Primitive FeNi metal grains in $\mathrm{CH}$ carbonaceous chondrites formed by condensation from a gas of solar composition. J. Geophys. Res. 104, 22053-22059.

Meibom A., Desch S. J., Krot A. N., Cuzzi J. N., Petaev M. I., Wilson L., and Keil K. (2000a) Large scale thermal events in the solar nebula recorded in Fe, Ni metal condensates in primitive meteorites. Science $\mathbf{2 8 8 ,} 839-841$. 
Meibom A., Krot A. N., Righter K., Chabot N., and Keil K. (2000b) Metal/SulfideFerrous Silicate Shock Melts in QUE94411 and Hammadah al Hamra 237: Remains of the Missing Matrix? Lunar Planet. Sci. Conf. XXXI, \#1420.

Morfill G. E. (1985) Physics and chemistry in the primitive solar nebula. In Birth and Infancy of Stars (eds. R. Lucas and A. Omant). North-Holland. pp. 693-794.

Newsom H. E. and Drake M. J. (1979) The origin of metal clasts in the Bencubbin meteorite breccia. Geochim. Cosmochim. Acta 43, 689-707.

Palme H. and Wlotzka F. (1976) A metal particle from a Ca,Al-rich inclusion from the meteorite Allende, and the condensation of refractory siderophile elements. Earth Planet. Sci. Lett. 33, 45-60.

Pernicka E. and Wasson J. T. (1987) Ru, Re, Os, Pt and Au in iron meteorites. Geochim. Cosmochim. Acta 51, 1717-1726.

Petaev M. I., Meibom A., Krot A. N., and Wood J. A. (1999) The condensation origin of some metal in $\mathrm{CH}$ chondrites: a thermodynamic model. Lunar Planet. Sci. Conf. $\mathbf{X X X}, \# 1613$.

Petaev M. I., Meibom A., Krot A. N., Wood J. A., and Keil K. (2000) The condensation origin of zoned metal grains in QUE94411: Implications for the formation of Bencubbin/CH-like chondrites. Lunar Planet. Sci. Conf. XXXI, \#1606.

Podosek F. A. and Cassen P. (1994) Theoretical, observational, and isotopic estimates of the lifetime of the solar nebula. Meteoritics 29, 6-25.

Radomsky P. M. and Hewins R. H. (1990) Formation conditions of pyroxene-olivine and magnesian olivine chondrules. Geochim. Cosmochim. Acta 54, 3475-3490.

Scott E. R. D. (1972) Chemical fractionation in iron meteorites and its interpretation. Geochim. Cosmochim. Acta 36, 1205-1236.

Scott E. R. D. (1988) A new kind of primitive chondrite, Allan Hills 85085. Earth Planet. Sci. Lett. 91, 1-18. 
Steele I. M. (1988) Primitive material surviving in meteorites: Mineral grains. In Meteorites and the Early Solar System (eds. J. F. Kerridge and M. S. Matthews). Univ. Arizona Press. pp. 808-818.

Sylvester P. J., Ward B. J., Grossman L., and Hutcheon I. D. (1990) Chemical compositions of siderophile element-rich opaque assemblages in an Allende inclusion. Geochim. Cosmochim. Acta 54, 3491-3508.

Weisberg M. K., Prinz M., and Nehru C. E. (1990) The Bencubbin chondrite breccia and its relationship to CR chondrites and the ALH85085 chondrite. Meteoritics 25, 269279.

Weisberg M. K., Prinz M., Clayton R. N., Mayeda T. K., Grady M. M., and Pillinger C. T. (1995) The CR chondrite clan. Proc. NIPR Symp. Antarct. Meteorites 8, 11-32.

Weisberg M. K., Prinz M., Clayton R. N., Mayeda T. K., Sugiura N., and Zashu S. (1998) The bencubbinite (B) group of the CR clan. Meteorit. Planet. Sci. 33, A166.

Weisberg M. K., Prinz M., Clayton R. N., Mayeda T. K., Sugiura N., Zashu S., and Ebihara M. (1999) QUE94411 and the origin of bencubbinites. Lunar Planet. Sci. Conf. XXX, \#1416.

Weisberg M. K., Prinz M., Clayton R. N., Mayeda T. K., Sugiura N., Zashu S., and Ebihara M. (2000a) A new metal-rich chondrite group. Submitted to Meteorit. Planet. Sci.

Weisberg M. K., Prinz M., Humayun M., and Campbell A. J. (2000b) Origin of metal in the CB (bencubbinite) chondrites. Lunar Planet. Sci. Conf. XXXI, \#1466.

Yamamoto T. and Hasegawa H. (1977) Grain formation through nucleation process in astrophysical environment. Prog. Theor. Phys. 58, 816-828.

Zanda B., Bourot-Denise M., Perron C., and Hewins R. H. (1994) Origin and metamorphic redistribution of silicon, chromium, and phosphorus in the metal of chondrites. Science, 265, 1846-1849. 
Zipfel J., Wlotzka F., and Spettel B. (1998) Bulk chemistry and mineralogy of a new "unique" metal-rich chondritic breccia, Hammadah al Hamra 237. Lunar Planet. Sci. Conf. XXIX, \#1417. 


\section{APPENDIX}

Table A1. Electron microprobe data from metal grains in QUE94411. Errors for each element are listed in the first row, and the detection limits are listed in the second row. $\mathrm{X}$ is distance across grain. Silicon was below detection $(<0.02 \mathrm{wt} \%)$ at all points.

\begin{tabular}{|c|c|c|c|c|c|c|c|c|c|c|c|c|c|}
\hline \multirow[b]{2}{*}{ Sample } & \multicolumn{3}{|c|}{ wt\%: } & \multirow[b]{2}{*}{$\mathrm{Fe}$} & \multirow[b]{2}{*}{ Co } & \multirow[b]{2}{*}{$\mathrm{Ni}$} & \multirow[b]{2}{*}{ Sample } & \multicolumn{3}{|c|}{ wt\%: } & \multirow[b]{2}{*}{$\mathrm{Fe}$} & \multirow[b]{2}{*}{ Co } & \multirow[b]{2}{*}{$\mathrm{Ni}$} \\
\hline & $X, \mu \mathrm{m}$ & $\mathrm{P}$ & $\mathrm{Cr}$ & & & & & $X, \mu \mathrm{m}$ & $\mathrm{P}$ & $\mathrm{Cr}$ & & & \\
\hline error & & \pm 0.02 & \pm 0.02 & \pm 0.5 & \pm 0.03 & \pm 0.1 & $\# 2$ & & & & & & \\
\hline det. limit & & 0.03 & 0.03 & 0.07 & 0.04 & 0.08 & & 277 & 0.09 & 0.15 & 89.0 & 0.48 & 10.3 \\
\hline \multirow[t]{31}{*}{$\# 1$} & & & & & & & & 293 & 0.07 & 0.15 & 89.3 & 0.45 & 10.1 \\
\hline & 0 & 0.15 & 0.13 & 95.1 & 0.22 & 4.3 & & 310 & 0.08 & 0.16 & 89.6 & 0.41 & 9.8 \\
\hline & 16 & 0.14 & 0.22 & 93.5 & 0.26 & 5.8 & & 326 & 0.09 & 0.17 & 90.1 & 0.44 & 9.3 \\
\hline & 32 & 0.11 & 0.18 & 91.8 & 0.37 & 7.5 & & 342 & 0.10 & 0.18 & 90.5 & 0.40 & 8.9 \\
\hline & 48 & 0.11 & 0.16 & 91.0 & 0.38 & 8.4 & & 359 & 0.11 & 0.21 & 91.6 & 0.35 & 7.8 \\
\hline & 64 & 0.10 & 0.15 & 90.1 & 0.41 & 9.2 & & 375 & 0.11 & 0.33 & 93.2 & 0.31 & 6.0 \\
\hline & 80 & 0.09 & 0.16 & 89.7 & 0.43 & 9.7 & & 391 & 0.14 & 0.43 & 94.9 & 0.23 & 4.3 \\
\hline & 96 & 0.08 & 0.15 & 89.0 & 0.50 & 10.3 & & & & & & & \\
\hline & 112 & 0.08 & 0.16 & 88.6 & 0.46 & 10.6 & \#4 & & & & & & \\
\hline & 128 & 0.08 & 0.16 & 88.1 & 0.48 & 11.1 & & 0 & 0.15 & 0.22 & 92.4 & 0.33 & 6.9 \\
\hline & 144 & 0.07 & 0.15 & 87.9 & 0.47 & 11.5 & & 13 & 0.14 & 0.19 & 91.4 & 0.37 & 7.9 \\
\hline & 160 & 0.07 & 0.14 & 87.5 & 0.47 & 11.7 & & 25 & 0.12 & 0.17 & 90.6 & 0.40 & 8.7 \\
\hline & 176 & 0.06 & 0.13 & 87.2 & 0.50 & 12.1 & & 38 & 0.13 & 0.16 & 90.3 & 0.41 & 9.0 \\
\hline & 192 & 0.05 & 0.13 & 87.2 & 0.51 & 12.2 & & 50 & 0.12 & 0.14 & 89.8 & 0.43 & 9.5 \\
\hline & 208 & 0.06 & 0.15 & 86.9 & 0.53 & 12.4 & & 63 & 0.11 & 0.15 & 89.6 & 0.44 & 9.8 \\
\hline & 224 & 0.05 & 0.15 & 86.8 & 0.54 & 12.5 & & 75 & 0.09 & 0.14 & 89.3 & 0.42 & 10.0 \\
\hline & 240 & 0.06 & 0.14 & 86.9 & 0.53 & 12.5 & & 88 & 0.09 & 0.13 & 88.9 & 0.46 & 10.4 \\
\hline & 256 & 0.05 & 0.15 & 87.1 & 0.49 & 12.2 & & 100 & 0.08 & 0.12 & 88.7 & 0.46 & 10.7 \\
\hline & 272 & 0.06 & 0.14 & 87.2 & 0.51 & 12.2 & & 113 & 0.09 & 0.14 & 88.3 & 0.47 & 11.1 \\
\hline & 288 & 0.06 & 0.15 & 87.4 & 0.51 & 11.9 & & 125 & 0.08 & 0.14 & 88.1 & 0.48 & 11.2 \\
\hline & 304 & 0.07 & 0.15 & 87.9 & 0.49 & 11.5 & & 138 & 0.08 & 0.12 & 88.0 & 0.47 & 11.3 \\
\hline & 320 & 0.08 & 0.16 & 88.0 & 0.49 & 11.3 & & 150 & 0.08 & 0.14 & 87.9 & 0.49 & 11.4 \\
\hline & 336 & 0.06 & 0.14 & 88.5 & 0.48 & 10.9 & & 163 & 0.06 & 0.12 & 87.9 & 0.51 & 11.5 \\
\hline & 352 & 0.07 & 0.15 & 88.6 & 0.51 & 10.7 & & 175 & 0.08 & 0.13 & 87.9 & 0.48 & 11.4 \\
\hline & 368 & 0.06 & 0.15 & 89.1 & 0.45 & 10.3 & & 188 & 0.08 & 0.13 & 87.8 & 0.48 & 11.5 \\
\hline & 384 & 0.07 & 0.16 & 89.5 & 0.44 & 9.9 & & 200 & 0.07 & 0.13 & 88.1 & 0.50 & 11.2 \\
\hline & 400 & 0.09 & 0.15 & 90.0 & 0.42 & 9.3 & & 213 & 0.08 & 0.14 & 88.3 & 0.49 & 10.9 \\
\hline & 416 & 0.10 & 0.17 & 90.7 & 0.38 & 8.7 & & 225 & 0.09 & 0.12 & 88.6 & 0.46 & 10.6 \\
\hline & 432 & 0.11 & 0.18 & 92.1 & 0.35 & 7.2 & & 238 & 0.09 & 0.13 & 89.1 & 0.45 & 10.2 \\
\hline & 448 & 0.12 & 0.19 & 94.1 & 0.27 & 5.3 & & 250 & 0.09 & 0.13 & 89.5 & 0.45 & 9.9 \\
\hline & & & & & & & & 263 & 0.12 & 0.15 & 89.8 & 0.42 & 9.5 \\
\hline \multirow[t]{18}{*}{$\# 2$} & & & & & & & & 275 & 0.11 & 0.15 & 90.2 & 0.41 & 9.1 \\
\hline & 0 & 0.12 & 0.21 & 90.9 & 0.35 & 8.4 & & 288 & 0.15 & 0.17 & 91.3 & 0.37 & 8.0 \\
\hline & 16 & 0.10 & 0.17 & 90.3 & 0.41 & 9.1 & & 300 & 0.18 & 0.25 & 93.1 & 0.29 & 6.1 \\
\hline & 33 & 0.11 & 0.18 & 89.8 & 0.40 & 9.5 & & & & & & & \\
\hline & 49 & 0.09 & 0.18 & 89.6 & 0.45 & 9.7 & $\# 5$ & & & & & & \\
\hline & 65 & 0.08 & 0.16 & 89.5 & 0.45 & 9.9 & & 0 & 0.10 & 0.17 & 93.1 & 0.29 & 6.2 \\
\hline & 82 & 0.07 & 0.15 & 89.3 & 0.46 & 10.1 & & 8 & 0.09 & 0.15 & 92.3 & 0.34 & 7.1 \\
\hline & 98 & 0.07 & 0.16 & 89.1 & 0.50 & 10.2 & & 16 & 0.09 & 0.15 & 91.6 & 0.37 & 7.8 \\
\hline & 114 & 0.06 & 0.15 & 89.0 & 0.46 & 10.4 & & 25 & 0.09 & 0.15 & 90.9 & 0.40 & 8.5 \\
\hline & 130 & 0.05 & 0.14 & 88.8 & 0.50 & 10.6 & & 33 & 0.08 & 0.13 & 90.5 & 0.43 & 8.8 \\
\hline & 147 & 0.05 & 0.16 & 88.6 & 0.49 & 10.8 & & 41 & 0.09 & 0.13 & 89.9 & 0.44 & 9.4 \\
\hline & 163 & 0.07 & 0.15 & 88.2 & 0.51 & 11.2 & & 49 & 0.08 & 0.13 & 89.7 & 0.42 & 9.7 \\
\hline & 179 & 0.06 & 0.14 & 88.0 & 0.50 & 11.4 & & 57 & 0.07 & 0.13 & 89.4 & 0.46 & 10.0 \\
\hline & 196 & 0.05 & 0.14 & 87.8 & 0.50 & 11.6 & & 66 & 0.07 & 0.11 & 89.0 & 0.45 & 10.4 \\
\hline & 212 & 0.06 & 0.14 & 87.9 & 0.54 & 11.5 & & 74 & 0.07 & 0.11 & 88.6 & 0.47 & 10.7 \\
\hline & 228 & 0.06 & 0.14 & 88.0 & 0.51 & 11.4 & & 82 & 0.07 & 0.14 & 88.4 & 0.47 & 10.9 \\
\hline & 245 & 0.07 & 0.14 & 88.4 & 0.47 & 11.0 & & 90 & 0.07 & 0.12 & 88.2 & 0.49 & 11.2 \\
\hline & 261 & 0.06 & 0.14 & 88.7 & 0.48 & 10.6 & & 98 & 0.07 & 0.13 & 88.0 & 0.48 & 11.3 \\
\hline
\end{tabular}


Table A1, continued.

\begin{tabular}{|c|c|c|c|c|c|c|c|c|c|c|c|c|c|}
\hline \multirow[b]{2}{*}{ Sample } & \multicolumn{3}{|c|}{ wt\%: } & \multirow[b]{2}{*}{$\mathrm{Fe}$} & \multirow[b]{2}{*}{$\mathrm{Co}$} & \multirow[b]{2}{*}{$\mathrm{Ni}$} & \multirow[b]{2}{*}{ Sample } & \multicolumn{3}{|c|}{ wt\%: } & \multirow[b]{2}{*}{$\mathrm{Fe}$} & \multirow[b]{2}{*}{ Co } & \multirow[b]{2}{*}{$\mathrm{Ni}$} \\
\hline & $\mathrm{X}, \mu \mathrm{m}$ & $\mathrm{P}$ & $\mathrm{Cr}$ & & & & & $\mathrm{X}, \mu \mathrm{m}$ & $\mathrm{P}$ & $\mathrm{Cr}$ & & & \\
\hline$\# 5$ & & & & & & & \#7 & & & & & & \\
\hline & 115 & 0.06 & 0.13 & 87.8 & 0.49 & 11.6 & & 102 & 0.07 & 0.12 & 88.5 & 0.45 & 10.9 \\
\hline & 123 & 0.07 & 0.13 & 87.8 & 0.46 & 11.6 & & 116 & 0.08 & 0.12 & 88.4 & 0.47 & 11.0 \\
\hline & 148 & 0.07 & 0.13 & 87.8 & 0.51 & 11.5 & & 160 & 0.08 & 0.12 & 87.8 & 0.50 & 11.6 \\
\hline & 156 & 0.07 & 0.13 & 87.8 & 0.50 & 11.6 & & 174 & 0.08 & 0.12 & 87.9 & 0.47 & 11.4 \\
\hline & 164 & 0.08 & 0.13 & 87.9 & 0.49 & 11.4 & & 189 & 0.08 & 0.13 & 87.6 & 0.51 & 11.7 \\
\hline & 172 & 0.07 & 0.13 & 88.2 & 0.48 & 11.2 & & 203 & 0.07 & 0.11 & 87.6 & 0.50 & 11.8 \\
\hline \multirow{22}{*}{ \#6A } & & & & & & & & 261 & 0.09 & 0.13 & 88.2 & 0.48 & 11.1 \\
\hline & & & & & & & & 276 & 0.09 & 0.13 & 88.7 & 0.48 & 10.6 \\
\hline & 0 & 0.07 & 0.22 & 92.3 & 0.33 & 6.8 & & 290 & 0.09 & 0.13 & 89.1 & 0.48 & 10.2 \\
\hline & 10 & 0.06 & 0.19 & 91.7 & 0.38 & 7.6 & & 305 & 0.10 & 0.13 & 89.8 & 0.42 & 9.6 \\
\hline & 20 & 0.06 & 0.17 & 90.8 & 0.42 & 8.6 & & 319 & 0.09 & 0.14 & 90.6 & 0.39 & 8.8 \\
\hline & 30 & 0.06 & 0.16 & 89.8 & 0.39 & 9.7 & & 334 & 0.12 & 0.18 & 91.8 & 0.34 & 7.7 \\
\hline & 40 & 0.06 & 0.15 & 89.0 & 0.47 & 10.4 & & 348 & 0.13 & 0.22 & 89.4 & 0.22 & 4.2 \\
\hline & 50 & 0.06 & 0.15 & 88.5 & 0.47 & 11.0 & & & & & & & \\
\hline & 60 & 0.07 & 0.14 & 87.7 & 0.52 & 11.7 & $\# 8$ & & & & & & \\
\hline & 70 & 0.06 & 0.15 & 87.4 & 0.52 & 11.9 & & 0 & 0.14 & 0.14 & 93.5 & 0.29 & 5.9 \\
\hline & 140 & 0.06 & 0.14 & 87.1 & 0.52 & 12.4 & & 67 & 0.11 & 0.14 & 92.6 & 0.34 & 6.8 \\
\hline & 150 & 0.05 & 0.14 & 87.1 & 0.52 & 12.4 & & 76 & 0.10 & 0.14 & 91.5 & 0.36 & 7.9 \\
\hline & 160 & 0.05 & 0.14 & 87.5 & 0.53 & 11.9 & & 86 & 0.09 & 0.14 & 90.6 & 0.40 & 8.9 \\
\hline & 170 & 0.06 & 0.13 & 87.7 & 0.51 & 11.7 & & 95 & 0.11 & 0.13 & 89.5 & 0.42 & 9.9 \\
\hline & 180 & 0.06 & 0.16 & 88.1 & 0.46 & 11.3 & & 105 & 0.09 & 0.13 & 88.4 & 0.48 & 11.1 \\
\hline & 190 & 0.06 & 0.14 & 88.5 & 0.48 & 10.9 & & 114 & 0.08 & 0.12 & 87.7 & 0.47 & 11.7 \\
\hline & 200 & 0.06 & 0.15 & 89.0 & 0.47 & 10.4 & & 124 & 0.09 & 0.13 & 87.3 & 0.47 & 12.2 \\
\hline & 210 & 0.06 & 0.15 & 89.7 & 0.43 & 9.8 & & 133 & 0.07 & 0.13 & 87.0 & 0.49 & 12.4 \\
\hline & 220 & 0.08 & 0.16 & 90.2 & 0.43 & 9.2 & & 143 & 0.07 & 0.12 & 86.8 & 0.51 & 12.6 \\
\hline & 230 & 0.05 & 0.18 & 90.9 & 0.38 & 8.5 & & 152 & 0.09 & 0.12 & 86.9 & 0.52 & 12.4 \\
\hline & 240 & 0.06 & 0.20 & 91.5 & 0.39 & 7.9 & & 162 & 0.09 & 0.12 & 87.1 & 0.52 & 12.3 \\
\hline & & & & & & & & 171 & 0.08 & 0.13 & 87.5 & 0.47 & 11.9 \\
\hline \multirow[t]{6}{*}{$\# 7$} & & & & & & & & 181 & 0.09 & 0.12 & 88.0 & 0.48 & 11.5 \\
\hline & 0 & 0.14 & 0.18 & 94.0 & 0.27 & 5.4 & & 190 & 0.09 & 0.13 & 88.8 & 0.44 & 10.6 \\
\hline & 15 & 0.14 & 0.21 & 93.4 & 0.28 & 6.0 & & 200 & 0.10 & 0.12 & 89.8 & 0.42 & 9.7 \\
\hline & 29 & 0.12 & 0.15 & 92.0 & 0.37 & 7.4 & & 209 & 0.11 & 0.14 & 90.9 & 0.42 & 8.5 \\
\hline & 44 & 0.12 & 0.15 & 90.9 & 0.39 & 8.5 & & 219 & 0.10 & 0.14 & 92.4 & 0.31 & 7.1 \\
\hline & 58 & 0.10 & 0.13 & 90.0 & 0.42 & 9.4 & & 228 & 0.13 & 0.17 & 93.5 & 0.28 & 5.9 \\
\hline
\end{tabular}


Table 1. Laser ablation ICP-MS data from metal grains in QUE94411. Elemental abundances at the detection limits are indicated by italics. $\mathrm{X}$ is distance across grain.

\begin{tabular}{|c|c|c|c|c|c|c|c|c|c|c|c|c|c|c|c|}
\hline \multirow[b]{2}{*}{ Sample } & \multicolumn{3}{|c|}{ wt\%: } & \multirow[b]{2}{*}{$\mathrm{Fe}$} & \multirow[b]{2}{*}{ Co } & \multicolumn{2}{|c|}{ ppm: } & \multirow[b]{2}{*}{$\mathrm{Ru}$} & \multirow[b]{2}{*}{$\mathrm{Rh}$} & \multirow[b]{2}{*}{$\mathrm{Pd}$} & \multirow[b]{2}{*}{ W } & \multirow[b]{2}{*}{$\operatorname{Re}$} & \multirow[b]{2}{*}{ Os } & \multirow[b]{2}{*}{ Ir } & \\
\hline & $\mathrm{X}, \mu \mathrm{m}$ & $\mathrm{P}$ & $\mathrm{Cr}$ & & & $\mathrm{Ni}$ & Mo & & & & & & & & $\mathrm{Pt}$ \\
\hline$\# 1$ & & & & & & & & & & & & & & & \\
\hline & 16 & 0.31 & 0.21 & 94 & 0.32 & 5.9 & 2.3 & 3.7 & 0.8 & 3.3 & 0.55 & 0.25 & 2.4 & 2.8 & 4.9 \\
\hline & 48 & 0.25 & 0.15 & 91 & 0.39 & 8.6 & 2.8 & 4.7 & 1.0 & 2.9 & 0.55 & 0.51 & 2.3 & 2.5 & 5.3 \\
\hline & 80 & 0.20 & 0.16 & 91 & 0.41 & 8.2 & 4.1 & 6.1 & 1.6 & 2.3 & 0.55 & 0.38 & 3.5 & 3.5 & 5.8 \\
\hline & 111 & 0.18 & 0.15 & 90 & 0.38 & 9.3 & 3.8 & 7.1 & 2.0 & 2.6 & 0.55 & 0.19 & 3.1 & 3.8 & 7.0 \\
\hline & 143 & 0.16 & 0.18 & 88 & 0.52 & 11.8 & 4.1 & 9.0 & 1.7 & 3.2 & 0.55 & 0.25 & 4.2 & 5.3 & 7.8 \\
\hline & 175 & 0.09 & 0.21 & 88 & 0.49 & 11.9 & 6.5 & 8.2 & 2.4 & 2.9 & 0.55 & 0.82 & 5.2 & 5.9 & 10.1 \\
\hline & 207 & 0.13 & 0.18 & 88 & 0.51 & 11.4 & 5.4 & 10.3 & 2.3 & 3.4 & 0.55 & 0.49 & 4.6 & 4.3 & 9.8 \\
\hline & 239 & 0.12 & 0.15 & 89 & 0.46 & 10.6 & 6.7 & 12.4 & 2.5 & 3.1 & 0.55 & 0.65 & 5.7 & 6.9 & 10.3 \\
\hline & 270 & 0.12 & 0.13 & 87 & 0.51 & 12.2 & 4.9 & 10.8 & 2.2 & 3.8 & 0.55 & 0.55 & 6.1 & 6.9 & 11.7 \\
\hline & 302 & 0.10 & 0.14 & 88 & 0.49 & 11.2 & 5.1 & 8.4 & 2.0 & 2.7 & 0.55 & 0.42 & 4.8 & 5.3 & 8.8 \\
\hline & 334 & 0.14 & 0.13 & 87 & 0.48 & 12.9 & 4.9 & 10.2 & 2.2 & 4.3 & 0.55 & 0.52 & 4.4 & 4.1 & 8.1 \\
\hline & 366 & 0.16 & 0.15 & 89 & 0.50 & 10.4 & 4.7 & 7.0 & 1.9 & 3.6 & 0.55 & 0.54 & 3.8 & 4.4 & 6.7 \\
\hline & 398 & 0.16 & 0.14 & 90 & 0.43 & 9.3 & 4.2 & 7.7 & 1.5 & 3.2 & 0.55 & 0.47 & 4.1 & 4.3 & 8.0 \\
\hline & 429 & 0.20 & 0.15 & 90 & 0.43 & 9.4 & 5.1 & 5.7 & 1.9 & 3.4 & 0.55 & 0.24 & 3.5 & 3.3 & 7.3 \\
\hline & 461 & 0.26 & 0.19 & 93 & 0.31 & 6.3 & 3.4 & 4.2 & 0.7 & 2.5 & 0.55 & 0.15 & 2.9 & 2.6 & 5.1 \\
\hline$\# 2$ & & & & & & & & & & & & & & & \\
\hline & 16 & 0.22 & 0.35 & 94 & 0.33 & 5.9 & 3.7 & 4.6 & 1.0 & 2.1 & 0.66 & 0.34 & 3.8 & 3.0 & 4.6 \\
\hline & 48 & 0.29 & 0.32 & 92 & 0.34 & 7.4 & 3.9 & 5.4 & 1.3 & 2.9 & 0.66 & 0.34 & 3.2 & 2.8 & 5.3 \\
\hline & 80 & 0.21 & 0.32 & 91 & 0.44 & 8.9 & 4.1 & 6.0 & 1.7 & 2.7 & 0.66 & 0.34 & 2.9 & 2.8 & 5.5 \\
\hline & 111 & 0.20 & 0.24 & 91 & 0.44 & 9.0 & 6.1 & 6.1 & 1.0 & 2.4 & 0.66 & 0.34 & 3.0 & 2.9 & 4.1 \\
\hline & 143 & 0.16 & 0.17 & 90 & 0.39 & 10.0 & 5.8 & 4.9 & 1.2 & 2.2 & 0.66 & 0.34 & 2.7 & 3.9 & 6.7 \\
\hline & 175 & 0.15 & 0.15 & 90 & 0.40 & 9.5 & 6.3 & 7.5 & 1.4 & 2.4 & 0.94 & 0.34 & 3.0 & 3.6 & 6.9 \\
\hline & 207 & 0.14 & 0.16 & 89 & 0.49 & 10.1 & 6.3 & 8.3 & 1.5 & 2.6 & 0.72 & 0.35 & 3.5 & 3.8 & 7.5 \\
\hline & 239 & 0.13 & 0.16 & 87 & 0.55 & 12.7 & 6.8 & 7.9 & 1.6 & 3.2 & 0.78 & 0.34 & 3.3 & 4.3 & 7.6 \\
\hline & 270 & 0.14 & 0.15 & 90 & 0.43 & 9.6 & 6.3 & 6.6 & 2.1 & 3.3 & 1.30 & 0.34 & 3.2 & 3.7 & 6.7 \\
\hline & 302 & 0.16 & 0.13 & 91 & 0.45 & 8.8 & 5.5 & 7.3 & 1.4 & 2.9 & 0.66 & 0.34 & 2.5 & 2.9 & 5.1 \\
\hline & 334 & 0.21 & 0.20 & 89 & 0.48 & 10.4 & 6.2 & 6.8 & 1.6 & 3.3 & 0.66 & 0.34 & 2.6 & 3.2 & 6.9 \\
\hline & 366 & 0.21 & 0.15 & 92 & 0.35 & 8.0 & 3.8 & 5.5 & 1.0 & 2.7 & 0.66 & 0.34 & 2.2 & 3.2 & 5.8 \\
\hline & 398 & 0.27 & 0.29 & 93 & 0.27 & 6.4 & 4.1 & 4.9 & 1.1 & 3.5 & 0.66 & 0.50 & 3.4 & 2.9 & 5.6 \\
\hline$\# 4$ & & & & & & & & & & & & & & & \\
\hline & 16 & 0.43 & 0.25 & 93 & 0.31 & 7.1 & 4.4 & 5.2 & 0.9 & 2.3 & 0.49 & 0.43 & 4.0 & 3.0 & 6.7 \\
\hline & 48 & 0.28 & 0.22 & 90 & 0.47 & 9.3 & 4.2 & 4.9 & 1.8 & 3.4 & 0.39 & 0.36 & 2.8 & 2.6 & 5.3 \\
\hline & 80 & 0.25 & 0.15 & 91 & 0.43 & 9.0 & 4.1 & 4.7 & 1.6 & 3.6 & 0.39 & 0.42 & 3.0 & 3.5 & 6.2 \\
\hline & 111 & 0.24 & 0.14 & 88 & 0.49 & 11.1 & 4.0 & 7.1 & 2.0 & 2.6 & 0.39 & 0.43 & 3.3 & 4.7 & 7.9 \\
\hline & 143 & 0.19 & 0.14 & 90 & 0.43 & 9.2 & 4.9 & 8.3 & 2.5 & 2.7 & 0.39 & 0.36 & 4.0 & 4.6 & 8.4 \\
\hline & 175 & 0.16 & 0.13 & 90 & 0.47 & 10.0 & 4.6 & 9.5 & 2.6 & 3.8 & 0.39 & 0.40 & 4.0 & 5.5 & 10.5 \\
\hline & 207 & 0.17 & 0.13 & 88 & 0.52 & 11.9 & 5.5 & 9.5 & 2.1 & 3.1 & 0.55 & 0.43 & 5.4 & 7.6 & 9.8 \\
\hline & 239 & 0.18 & 0.13 & 91 & 0.43 & 8.8 & 4.2 & 6.3 & 1.6 & 3.4 & 0.39 & 0.38 & 3.2 & 3.8 & 6.5 \\
\hline & 270 & 0.25 & 0.17 & 88 & 0.49 & 11.3 & 5.9 & 7.8 & 2.0 & 3.3 & 0.39 & 0.36 & 3.2 & 4.0 & 7.0 \\
\hline & 302 & 0.28 & 0.14 & 90 & 0.41 & 9.2 & 3.4 & 5.1 & 1.6 & 3.5 & 0.48 & 0.36 & 3.7 & 3.5 & 6.1 \\
\hline & 334 & 0.24 & 0.27 & 93 & 0.32 & 6.9 & 2.7 & 4.6 & 1.0 & 2.9 & 0.39 & 0.36 & 4.7 & 4.1 & 6.8 \\
\hline$\# 5$ & & & & & & & & & & & & & & & \\
\hline & 16 & 0.19 & 0.11 & 92 & 0.33 & 7.4 & 4.5 & 3.9 & 1.1 & 3.2 & 2.1 & 0.29 & 3.9 & 3.6 & 6.2 \\
\hline & 47 & 0.20 & 0.13 & 90 & 0.47 & 9.5 & 4.7 & 7.3 & 1.5 & 3.6 & 2.1 & 0.34 & 4.4 & 5.0 & 9.0 \\
\hline & 78 & 0.20 & 0.11 & 90 & 0.40 & 9.7 & 5.1 & 7.7 & 1.7 & 4.0 & 2.1 & 0.43 & 4.4 & 5.6 & 8.7 \\
\hline & 109 & 0.16 & 0.11 & 89 & 0.41 & 10.1 & 5.9 & 7.5 & 2.2 & 3.0 & 2.1 & 0.29 & 4.3 & 5.0 & 8.2 \\
\hline & 141 & 0.12 & 0.10 & 89 & 0.48 & 10.6 & 5.1 & 7.9 & 2.0 & 3.4 & 2.1 & 0.51 & 4.0 & 5.2 & 9.0 \\
\hline & 172 & 0.12 & 0.11 & 89 & 0.50 & 10.0 & 6.5 & 9.6 & 2.0 & 3.1 & 2.1 & 0.68 & 4.0 & 4.8 & 9.0 \\
\hline & 203 & 0.09 & 0.10 & 90 & 0.41 & 9.4 & 6.3 & 8.7 & 2.6 & 3.6 & 2.1 & 0.35 & 4.6 & 5.5 & 8.7 \\
\hline & 234 & 0.09 & 0.11 & 87 & 0.48 & 12.4 & 6.9 & 10.5 & 2.0 & 5.6 & 2.1 & 0.29 & 4.4 & 5.2 & 10.3 \\
\hline & 266 & 0.13 & 0.13 & 89 & 0.52 & 10.4 & 6.7 & 9.3 & 2.1 & 3.9 & 2.1 & 0.53 & 5.4 & 5.6 & 10.4 \\
\hline & 297 & 0.10 & 0.11 & 91 & 0.44 & 8.5 & 5.4 & 8.2 & 1.7 & 3.4 & 2.1 & 0.46 & 5.2 & 4.8 & 9.6 \\
\hline \#6A & & & & & & & & & & & & & & & \\
\hline & 16 & 0.15 & 0.22 & 90 & 0.44 & 9.7 & 6.5 & 6.0 & 1.3 & 3.9 & 0.41 & 0.54 & 4.8 & 4.4 & 7.1 \\
\hline & 47 & 0.14 & 0.16 & 89 & 0.39 & 10.5 & 6.4 & 6.7 & 1.6 & 3.2 & 0.31 & 0.47 & 4.7 & 4.8 & 8.4 \\
\hline
\end{tabular}


Table 1, continued.

\begin{tabular}{|c|c|c|c|c|c|c|c|c|c|c|c|c|c|c|c|}
\hline \multirow[b]{2}{*}{ Sample } & \multicolumn{3}{|c|}{ wt\%: } & \multicolumn{6}{|c|}{ ppm: } & \multirow[b]{2}{*}{$\mathrm{Pd}$} & \multirow[b]{2}{*}{ W } & \multirow[b]{2}{*}{$\mathrm{Re}$} & \multirow[b]{2}{*}{ Os } & \multirow[b]{2}{*}{ Ir } & \multirow[b]{2}{*}{$\mathrm{Pt}$} \\
\hline & $\mathrm{X}, \mu \mathrm{m}$ & $\mathrm{P}$ & $\mathrm{Cr}$ & $\mathrm{Fe}$ & Co & $\mathrm{Ni}$ & Mo & $\mathrm{Ru}$ & $\mathrm{Rh}$ & & & & & & \\
\hline \multirow[t]{7}{*}{ \#6A } & & & & & & & & & & & & & & & \\
\hline & 78 & 0.14 & 0.12 & 89 & 0.60 & 10.5 & 6.3 & 9.0 & 2.5 & 4.6 & 0.31 & 0.61 & 6.0 & 5.9 & 11.1 \\
\hline & 109 & 0.14 & 0.11 & 88 & 0.53 & 11.2 & 7.0 & 9.9 & 2.5 & 5.4 & 0.31 & 0.36 & 5.0 & 5.2 & 10.4 \\
\hline & 141 & 0.14 & 0.13 & 88 & 0.50 & 11.4 & 7.4 & 9.8 & 2.6 & 4.7 & 0.31 & 0.58 & 5.5 & 6.2 & 11.4 \\
\hline & 172 & 0.14 & 0.11 & 89 & 0.44 & 10.8 & 7.0 & 9.8 & 2.8 & 5.4 & 0.31 & 0.61 & 6.5 & 5.5 & 11.9 \\
\hline & 203 & 0.14 & 0.13 & 90 & 0.45 & 9.6 & 6.2 & 9.8 & 2.3 & 2.9 & 0.31 & 0.72 & 7.2 & 6.7 & 12.4 \\
\hline & 234 & 0.14 & 0.17 & 92 & 0.33 & 7.2 & 6.7 & 6.8 & 0.9 & 2.4 & 0.81 & 0.47 & 4.4 & 3.5 & 7.1 \\
\hline \multicolumn{16}{|l|}{$\# 7$} \\
\hline & 16 & 0.32 & 0.14 & 90 & 0.46 & 9.3 & 6.6 & 8.7 & 1.5 & 3.4 & 0.56 & 0.56 & 4.9 & 5.4 & 8.5 \\
\hline & 47 & 0.24 & 0.12 & 89 & 0.44 & 10.1 & 4.7 & 6.1 & 1.9 & 3.7 & 0.80 & 0.41 & 3.9 & 4.0 & 7.0 \\
\hline & 78 & 0.18 & 0.11 & 90 & 0.45 & 9.3 & 4.4 & 6.5 & 1.8 & 3.1 & 0.56 & 0.41 & 3.2 & 3.4 & 7.3 \\
\hline & 109 & 0.17 & 0.12 & 89 & 0.41 & 9.8 & 5.2 & 10.3 & 1.6 & 3.0 & 0.56 & 0.45 & 3.9 & 5.2 & 7.6 \\
\hline & 141 & 0.15 & 0.10 & 89 & 0.46 & 10.7 & 5.8 & 9.4 & 2.0 & 3.0 & 0.56 & 0.46 & 5.1 & 6.4 & 8.9 \\
\hline & 172 & 0.16 & 0.13 & 89 & 0.47 & 10.6 & 5.0 & 8.3 & 2.0 & 3.8 & 0.66 & 0.41 & 4.0 & 4.4 & 7.4 \\
\hline & 203 & 0.13 & 0.13 & 90 & 0.43 & 8.9 & 6.0 & 6.6 & 1.7 & 2.9 & 0.56 & 0.41 & 2.9 & 3.4 & 6.1 \\
\hline & 234 & 0.20 & 0.14 & 89 & 0.46 & 10.2 & 6.2 & 9.0 & 1.8 & 4.6 & 0.56 & 0.41 & 3.4 & 3.9 & 9.6 \\
\hline & 266 & 0.18 & 0.12 & 90 & 0.40 & 9.5 & 6.3 & 6.6 & 1.8 & 3.6 & 0.56 & 0.41 & 4.1 & 3.6 & 7.8 \\
\hline & 297 & 0.24 & 0.14 & 91 & 0.44 & 8.5 & 6.5 & 6.7 & 1.2 & 3.9 & 0.56 & 0.56 & 4.4 & 4.8 & 9.7 \\
\hline & 328 & 0.23 & 0.20 & 93 & 0.33 & 6.4 & 4.8 & 5.3 & 1.1 & 4.8 & 0.62 & 0.41 & 4.8 & 4.7 & 7.3 \\
\hline \multicolumn{16}{|l|}{ \#8 } \\
\hline & 14 & 0.28 & 0.16 & 95 & 0.25 & 4.6 & 4.4 & 3.0 & 0.9 & 3.6 & 1.2 & 0.59 & 2.9 & 2.3 & 5.3 \\
\hline & 41 & 0.24 & 0.14 & 91 & 0.39 & 7.9 & 4.8 & 5.5 & 0.9 & 4.0 & 1.2 & 0.59 & 3.3 & 3.2 & 6.1 \\
\hline & 69 & 0.24 & 0.12 & 90 & 0.39 & 9.4 & 5.3 & 8.3 & 1.9 & 3.4 & 1.2 & 0.65 & 5.9 & 5.6 & 10.9 \\
\hline & 96 & 0.20 & 0.11 & 89 & 0.42 & 10.7 & 4.7 & 8.1 & 2.6 & 3.4 & 1.2 & 0.59 & 6.0 & 6.2 & 11.1 \\
\hline & 124 & 0.19 & 0.09 & 90 & 0.38 & 9.4 & 3.5 & 6.9 & 2.1 & 4.0 & 1.2 & 0.59 & 6.9 & 5.2 & 10.3 \\
\hline & 151 & 0.22 & 0.12 & 89 & 0.37 & 10.1 & 4.5 & 9.7 & 2.1 & 3.0 & 1.2 & 0.59 & 6.0 & 5.4 & 11.0 \\
\hline & 179 & 0.22 & 0.11 & 92 & 0.30 & 7.3 & 4.9 & 7.0 & 1.2 & 4.2 & 1.2 & 0.59 & 4.2 & 3.6 & 6.8 \\
\hline$\# 10$ & & & & & & & & & & & & & & & \\
\hline & 16 & 0.67 & 0.29 & 90 & 0.39 & 8.9 & 5.6 & 5.3 & 1.1 & 3.7 & 2.5 & 0.34 & 3.0 & 4.0 & 6.3 \\
\hline & 47 & 0.62 & 0.25 & 91 & 0.31 & 7.7 & 4.6 & 4.7 & 1.0 & 3.1 & 2.4 & 0.31 & 2.8 & 3.2 & 4.9 \\
\hline & 78 & 0.64 & 0.27 & 91 & 0.36 & 7.7 & 6.3 & 5.0 & 1.0 & 3.1 & 3.5 & 0.31 & 3.5 & 3.3 & 5.7 \\
\hline & 109 & 0.57 & 0.29 & 91 & 0.31 & 7.3 & 5.3 & 5.1 & 1.0 & 2.8 & 2.2 & 0.37 & 2.7 & 3.1 & 5.6 \\
\hline & 141 & 0.64 & 0.28 & 90 & 0.40 & 8.5 & 6.4 & 6.4 & 1.0 & 4.3 & 4.1 & 0.31 & 3.6 & 3.3 & 5.6 \\
\hline & 172 & 0.64 & 0.29 & 91 & 0.41 & 7.9 & 5.2 & 4.8 & 1.0 & 3.3 & 2.7 & 0.31 & 3.2 & 3.2 & 5.1 \\
\hline & 203 & 0.70 & 0.26 & 90 & 0.44 & 9.1 & 6.8 & 6.4 & 1.0 & 2.9 & 2.8 & 0.42 & 3.7 & 4.1 & 5.7 \\
\hline & 234 & 0.63 & 0.28 & 90 & 0.38 & 8.9 & 6.6 & 4.9 & 1.0 & 3.2 & 3.4 & 0.32 & 3.4 & 3.1 & 6.2 \\
\hline & 266 & 0.63 & 0.28 & 91 & 0.35 & 8.2 & 6.0 & 4.7 & 1.0 & 4.4 & 3.2 & 0.49 & 3.0 & 3.1 & 5.3 \\
\hline & 297 & 0.63 & 0.30 & 90 & 0.38 & 9.0 & 7.4 & 6.0 & 1.2 & 4.0 & 2.3 & 0.35 & 3.8 & 3.7 & 7.2 \\
\hline & 328 & 0.79 & 0.33 & 88 & 0.39 & 10.0 & 6.7 & 6.6 & 1.0 & 4.3 & 4.3 & 0.46 & 3.6 & 3.8 & 6.7 \\
\hline & 359 & 0.68 & 0.29 & 89 & 0.42 & 9.4 & 6.8 & 6.4 & 1.0 & 4.0 & 3.3 & 0.38 & 3.2 & 4.0 & 6.7 \\
\hline & 391 & 0.59 & 0.35 & 90 & 0.38 & 8.5 & 7.8 & 6.6 & 1.0 & 4.7 & 3.8 & 0.33 & 4.2 & 4.1 & 7.1 \\
\hline$\# 11$ & & & & & & & & & & & & & & & \\
\hline & 75 & 0.53 & 0.17 & 92 & 0.30 & 6.5 & 4.7 & 5.9 & 1.7 & 3.2 & 0.71 & 0.43 & 4.0 & 3.9 & 7.4 \\
\hline & 125 & 0.52 & 0.15 & 93 & 0.29 & 5.8 & 4.1 & 4.6 & 1.2 & 3.2 & 0.67 & 0.36 & 4.2 & 3.4 & 5.7 \\
\hline & 175 & 0.50 & 0.22 & 93 & 0.29 & 6.3 & 4.8 & 4.7 & 0.8 & 3.7 & 0.39 & 0.48 & 3.4 & 4.0 & 5.3 \\
\hline & 225 & 0.50 & 0.13 & 93 & 0.29 & 6.2 & 4.7 & 4.4 & 0.9 & 3.4 & 0.81 & 0.36 & 3.3 & 3.4 & 5.2 \\
\hline & 275 & 0.48 & 0.18 & 93 & 0.30 & 6.0 & 3.1 & 4.2 & 1.1 & 3.2 & 0.83 & 0.36 & 2.8 & 4.0 & 5.9 \\
\hline & 325 & 0.55 & 0.18 & 92 & 0.30 & 7.4 & 4.1 & 6.5 & 0.9 & 3.4 & 0.78 & 0.36 & 4.3 & 3.7 & 6.1 \\
\hline & 375 & 0.47 & 0.14 & 93 & 0.30 & 6.0 & 4.1 & 5.7 & 1.3 & 3.7 & 0.90 & 0.43 & 3.4 & 3.8 & 5.7 \\
\hline & 425 & 0.47 & 0.19 & 93 & 0.30 & 6.5 & 3.5 & 5.6 & 1.2 & 2.6 & 0.94 & 0.43 & 4.1 & 3.9 & 6.5 \\
\hline & 475 & 0.52 & 0.16 & 93 & 0.27 & 5.8 & 3.9 & 5.0 & 1.1 & 3.2 & 1.06 & 0.36 & 3.7 & 3.6 & 6.3 \\
\hline & 525 & 0.41 & 0.20 & 93 & 0.29 & 6.2 & 3.8 & 5.5 & 0.9 & 3.7 & 1.28 & 0.36 & 3.6 & 4.3 & 6.4 \\
\hline & 575 & 0.51 & 0.17 & 92 & 0.29 & 6.9 & 3.6 & 4.6 & 1.2 & 3.0 & 1.08 & 0.36 & 3.6 & 3.7 & 6.9 \\
\hline & 625 & 0.49 & 0.08 & 93 & 0.28 & 5.8 & 4.3 & 6.2 & 1.3 & 2.7 & 1.43 & 0.46 & 4.2 & 3.6 & 7.5 \\
\hline & 675 & 0.55 & 0.12 & 93 & 0.27 & 6.2 & 4.3 & 5.0 & 1.2 & 3.3 & 1.10 & 0.41 & 3.9 & 3.8 & 6.5 \\
\hline & 725 & 0.67 & 0.10 & 93 & 0.27 & 6.0 & 4.1 & 6.4 & 1.3 & 3.7 & 0.73 & 0.39 & 4.7 & 4.2 & 6.7 \\
\hline & 775 & 0.55 & 0.09 & 93 & 0.32 & 6.0 & 4.9 & 10.4 & 1.3 & 4.3 & 1.79 & 0.36 & 7.9 & 15.3 & 11.8 \\
\hline
\end{tabular}


Table 2. Parameters used in modelling condensation of alloy metal from the solar nebula. A and B (Hultgren et al., 1973a) are used to describe the vapor pressure of each element over its metal (equation (3)). $\gamma$ is the activity coefficient of each element in the alloy (Hultgren et al., 1973b). C is the solar abundance of the element relative to $1 \times 10^{6} \mathrm{Si}$ atoms (Anders and Grevesse, 1989). K, the equilibrium constant for each oxide gas species, is determined from $\log \mathrm{K}=-\mathrm{A} / \mathrm{T}+\mathrm{B}$ (Chase, 1998).

\begin{tabular}{lrrrr}
\hline & $\mathrm{C}$ & $\mathrm{A}$ & $\mathrm{B}$ & $\gamma$ \\
\hline $\mathrm{V}$ & 293 & 26280 & 7.5084 & 0.045 \\
$\mathrm{Fe}$ & 900000 & 20589 & 6.9065 & 1 \\
$\mathrm{Co}$ & 2250 & 21415 & 6.9534 & 1.05 \\
$\mathrm{Ni}$ & 49300 & 21392 & 6.9873 & 0.65 \\
$\mathrm{Mo}$ & 2.55 & 33804 & 7.3991 & 1 \\
$\mathrm{Ru}$ & 1.86 & 33853 & 8.0657 & 1 \\
$\mathrm{Rh}$ & 0.344 & 28455 & 7.5676 & 1 \\
$\mathrm{Pd}$ & 1.39 & 19081 & 6.066 & 0.41 \\
$\mathrm{~W}$ & 0.133 & 45016 & 7.9608 & 1 \\
$\mathrm{Re}$ & 0.0517 & 39925 & 7.3298 & 1 \\
$\mathrm{Os}$ & 0.675 & 40893 & 7.9835 & 1 \\
$\mathrm{Ir}$ & 0.661 & 34517 & 7.7413 & 1 \\
$\mathrm{Pt}$ & 1.34 & 29195 & 7.5884 & 1 \\
$\mathrm{Au}$ & 0.187 & 18030 & 5.8323 & 1 \\
$\mathrm{VO}$ & & 5871.5 & 4.2498 & \\
$\mathrm{VO}_{2}$ & & -12816 & 0.8118 & \\
$\mathrm{FeO}$ & & 11694 & 4.2937 & \\
$\mathrm{MoO}$ & & 15676 & 5.1635 & \\
$\mathrm{MoO}_{2}$ & & -989.72 & 1.5798 & \\
$\mathrm{MoO}_{3}$ & & -18290 & -2.9997 & \\
$\mathrm{WO}$ & & 21588 & 5.1394 & \\
$\mathrm{WO}_{2}$ & 3492.5 & 1.8504 & \\
$\mathrm{~W}_{3} \mathrm{O}_{8}$ & & -87488 & -19.706 & \\
$\mathrm{WO}_{3}$ & -15397 & -2.9582 & \\
$\left(\mathrm{WO}_{3}\right)_{2}$ & & -59460 & -11.957 & \\
$\left(\mathrm{WO}_{3}\right)_{3}$ & & -103434 & -23.986 & \\
$\left(\mathrm{WO}_{3}\right)_{4}$ & & -142990 & -34.839 & \\
\hline
\end{tabular}


Table 3. Comparison between timescales of condensation and diffusion. Temperatures are representative of Fe-Ni alloy condensing from a gas of solar composition at the specified pressure. The timescales $\tau_{\text {cond }}$ and $\tau_{\text {diff }}$ are calculated from equations (10) and (11), respectively, for a grain of $400 \mu \mathrm{m}$ diameter and a diffusion length scale of $30 \mu \mathrm{m}$.

\begin{tabular}{rrrr}
\hline Pressure, Pa & Temperature, K & $\tau_{\text {cond }}$, days & $\tau_{\text {diff, }}$, days \\
\hline 100 & 1435 & 3.8 & 10 \\
10 & 1340 & 36 & 68 \\
1 & 1260 & 350 & 420 \\
0.1 & 1185 & 3400 & 2900 \\
\hline
\end{tabular}




\section{FIGURE CAPTIONS}

Figure 1. Nickel $\mathrm{K}_{\alpha}$ map of a section of QUE94411. Image is $10 \mathrm{~mm}$ across. Bright regions $=$ high $\mathrm{Ni}$ content; dark regions $=$ low $\mathrm{Ni}$ content. Zoning is visible in many of the grains with the highest $\mathrm{Ni}$ concentrations. Several large $(\sim 1 \mathrm{~mm})$ metal aggregates are readily observed, and many other homogeneous grains of varying $\mathrm{Ni}$ contents are also visible in this image. Black regions indicate silicates. The grains that were analyzed in this study are identified by a number to the left of each grain.

Figure 2. Electron microprobe trace across metal grain \#1 in QUE94411. The grain is zoned with $\mathrm{Ni}$ and $\mathrm{Co}$, which are more refractory than $\mathrm{Fe}$, enriched in the core, and $\mathrm{P}$ and $\mathrm{Cr}$, which are more volatile than $\mathrm{Fe}$, depleted in the core relative to chondritic abundances.

Figure 3. LA-ICP-MS profiles across grain \#1 in QUE94411. Data are normalized to CI chondrite abundances (Anders and Grevesse, 1989) and Fe. Errors on these data are about $11 \%(1 \sigma)$. The PGEs, with the exception of Pd, are more refractory than Fe and are zoned with enrichment in the core. Palladium has a volatility similar to that of Fe and is not zoned.

Figure 4. LA-ICP-MS profiles across grain \#8 in QUE94411. Data are normalized to CI chondrite abundances (Anders and Grevesse, 1989) and Fe. Errors on these data are about $11 \%(1 \sigma)$. The PGEs, with the exception of Pd, are more refractory than Fe and are zoned with enrichment in the core. Palladium has a volatility similar to that of Fe and is not zoned.

Figure 5. LA-ICP-MS profiles across grain \#11 in QUE94411. Data are normalized to CI chondrite abundances (Anders and Grevesse, 1989) and Fe. Errors on these data are about $11 \%(1 \sigma)$. This metal grain is unzoned. 
Figure 6. PGE vs. Ni plots for measured compositions in Grain 1 (filled symbols), compared to the calculated trajectory (open symbols, indicating $5 \mathrm{~K}$ temperature steps) during equilibrium condensation from a solar gas at $\mathrm{P}_{\text {tot }}=10 \mathrm{~Pa}$, with temperature ranging from $1360 \mathrm{~K}$ (at high Ni concentration) to $1260 \mathrm{~K}$ (at low Ni concentration). Also shown are magmatic crystallization trends for IIAB (dotted line) and IIIAB (dashed line) irons (Scott, 1972); the measured zoning is inconsistent with fractional crystallization.

Figure 7. PGE vs. Ni plots for measured compositions in Grain 8 (filled symbols), compared to the calculated trajectory (open symbols, indicating $5 \mathrm{~K}$ temperature steps) during equilibrium condensation from a solar gas at $\mathrm{P}_{\text {tot }}=10 \mathrm{~Pa}$, with temperature ranging from $1360 \mathrm{~K}$ (at high Ni concentration) to $1260 \mathrm{~K}$ (at low Ni concentration). Also shown are magmatic crystallization trends for IIAB (dotted line) and IIIAB (dashed line) irons (Scott, 1972); the measured zoning is inconsistent with fractional crystallization.

Figure 8. Siderophile element abundances in metal grains in QUE94411. Open and closed circles, unzoned grains (\#11 and \#10, respectively); open triangles, rim of zoned grain (\#1, average of 4 points); closed triangles, core of zoned grain (\#1, average of 4 points). Error bars represent one standard deviation.

Figure 9. Equilibrium condensation curves for siderophile elements condensing into a metallic alloy from a gas of solar composition. $\mathrm{P}_{\text {tot }}=10 \mathrm{~Pa}\left(10^{-4}\right.$ bar $)$. Note the similarity of the Pd and Fe curves, and the distinction between the refractory siderophiles and Fe. The refractory siderophiles are almost completely condensed before $\mathrm{Ni}$ and $\mathrm{Fe}$ begin condensing.

Figure 10. Iridium vs. Ni trajectories calculated for equilibrium condensation for a solar gas at varying pressures. 
Figure 11. Model of siderophile element profiles expected from equilibrium fractional condensation of a solar gas. Highly refractory siderophiles, represented here by Ir, are highly concentrated at the center of the grain and negligible elsewhere.

Figure 12. Siderophile element profiles calculated from a model of fractional condensation of a rapidly cooling, supersaturated gas of initially solar composition. A low nucleation rate permits only a small fraction of the siderophiles to condense at high temperature, so they remain supersaturated in the gas and are able to condense onto the grain at lower temperatures. 
\#W0332: Campbell et al., Figure 1

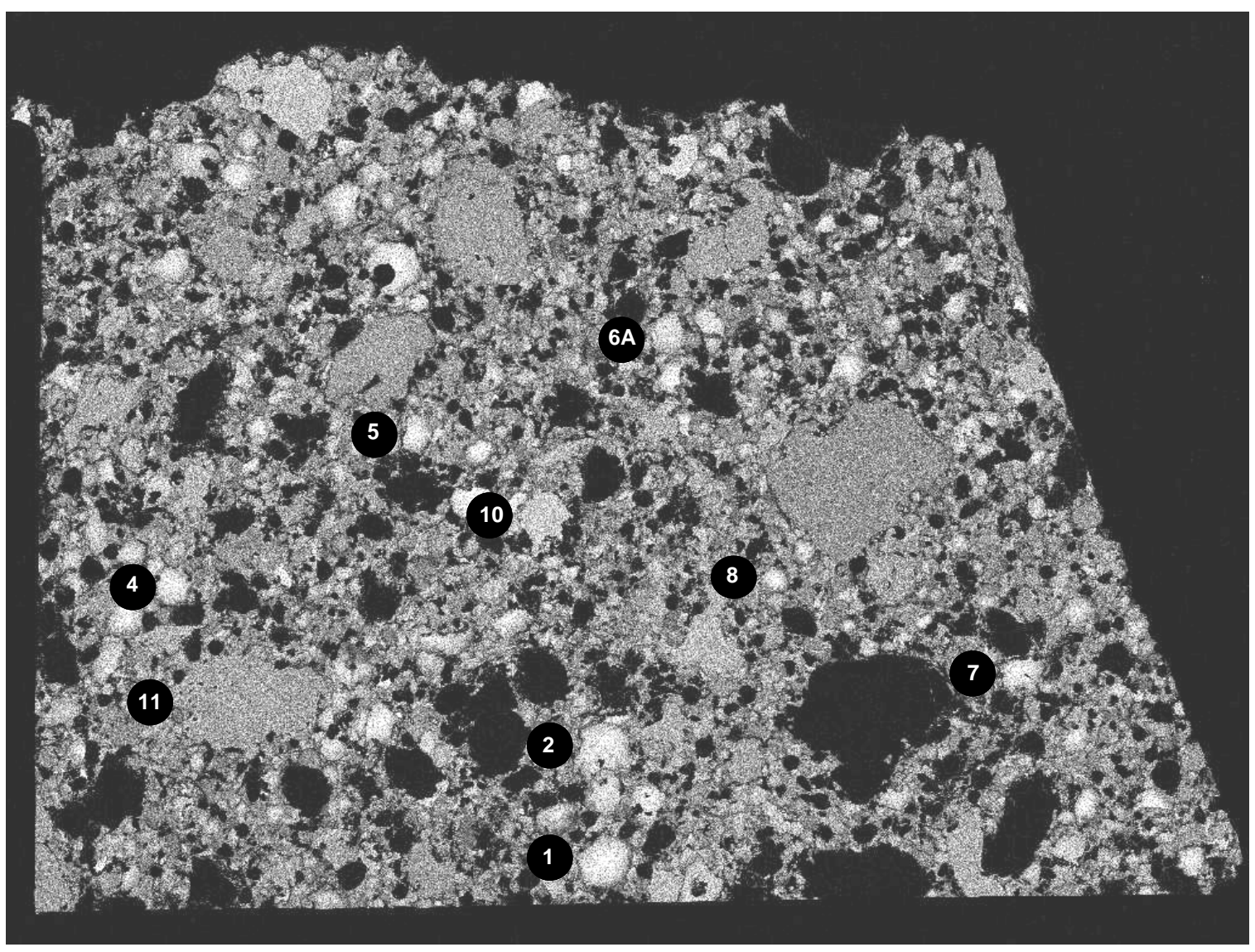


\#W0332: Campbell et al., Figure 2

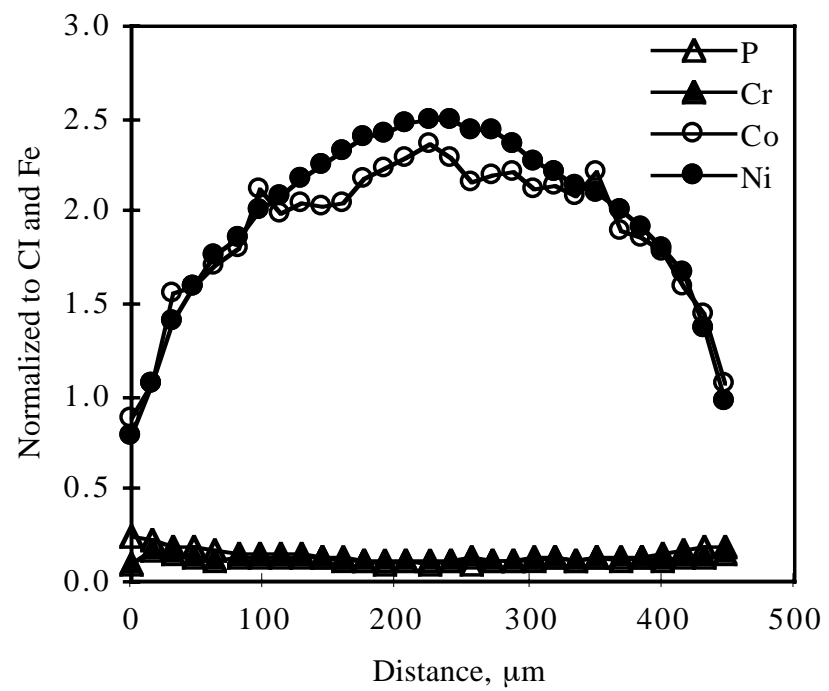


\#W0332: Campbell et al., Figure 3
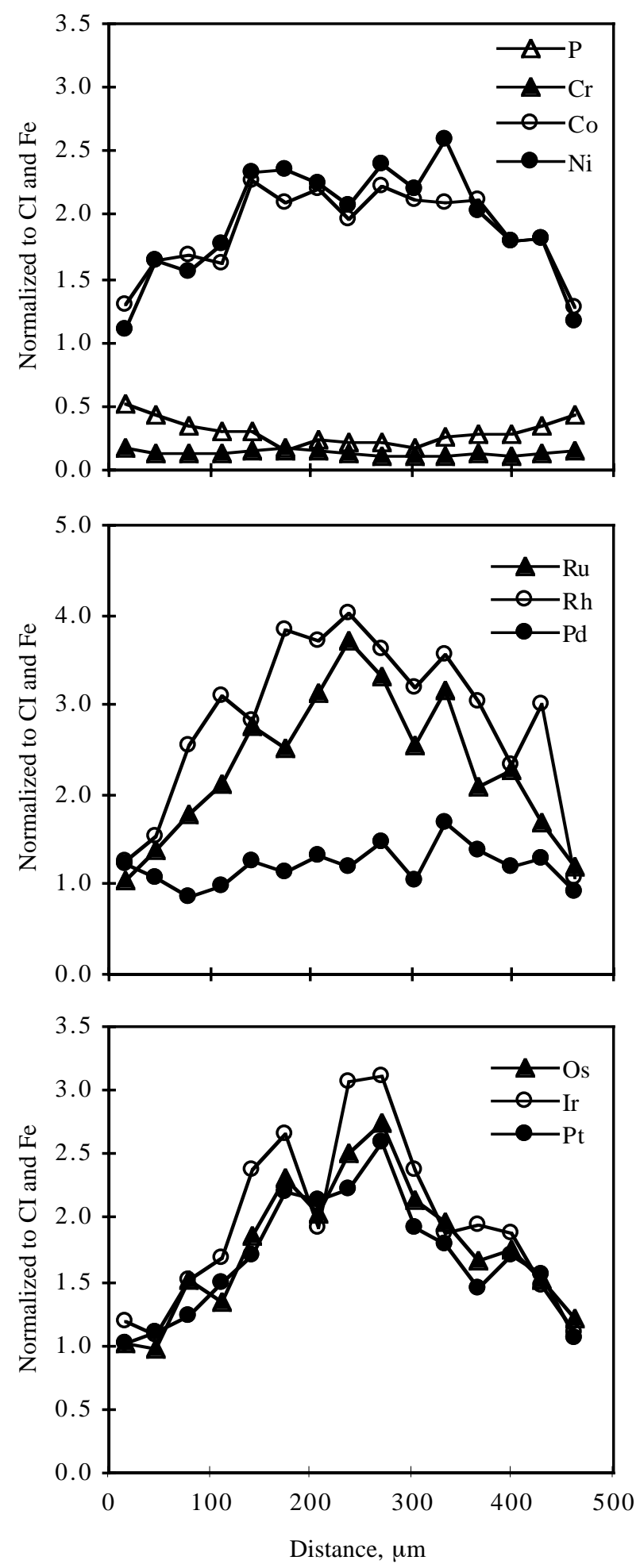
\#W0332: Campbell et al., Figure 4
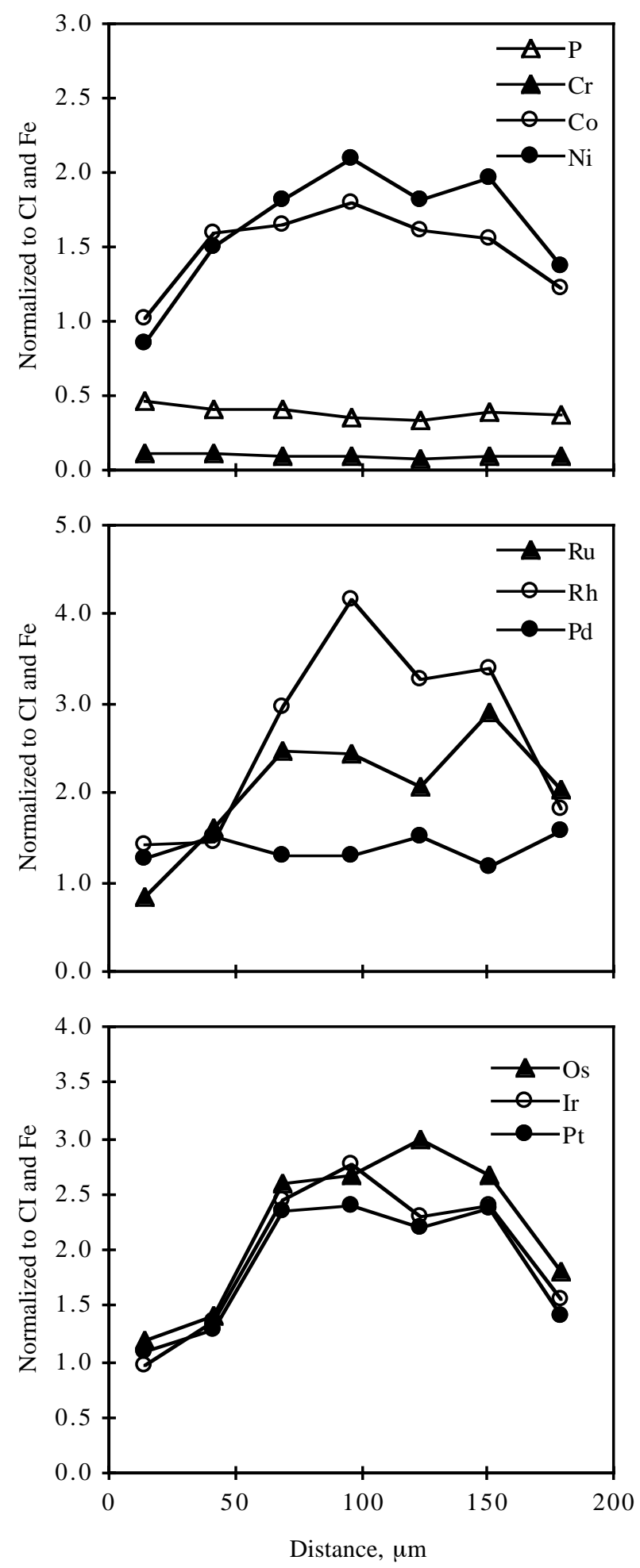
\#W0332: Campbell et al., Figure 5
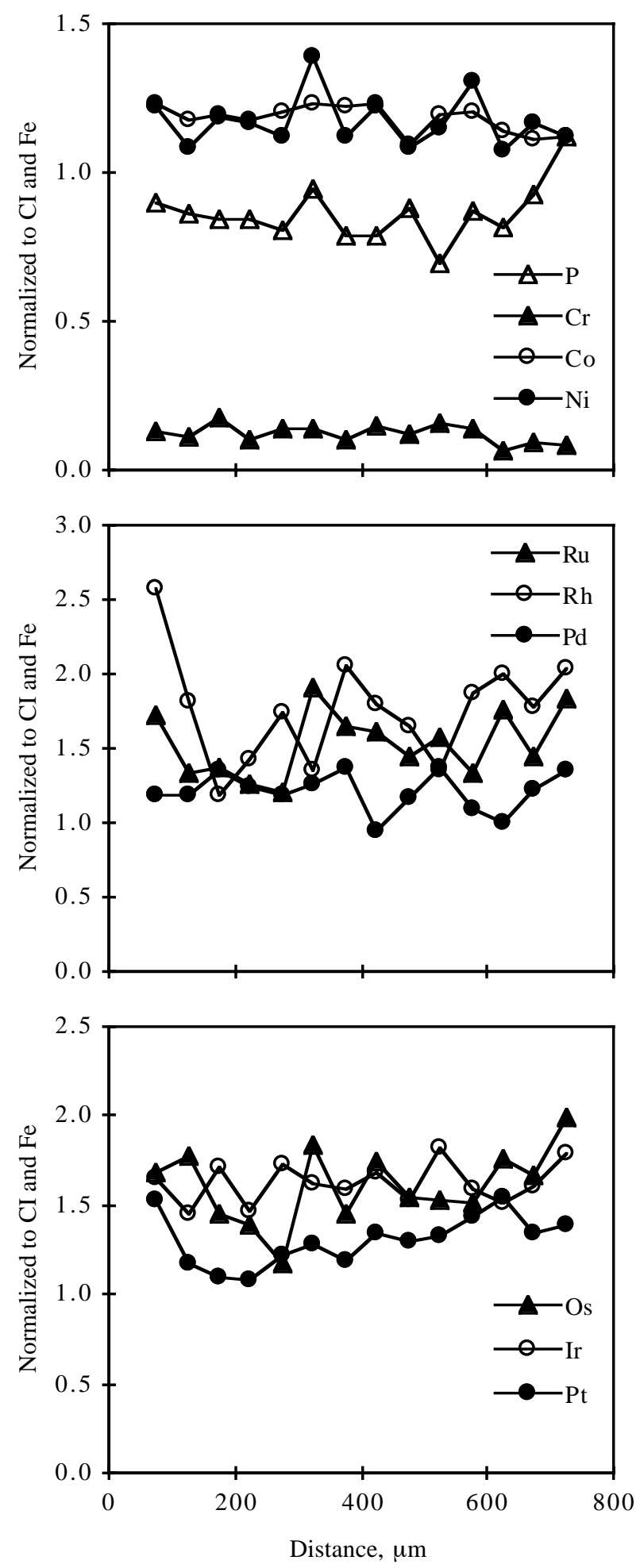
\#W0332: Campbell et al., Figure 6
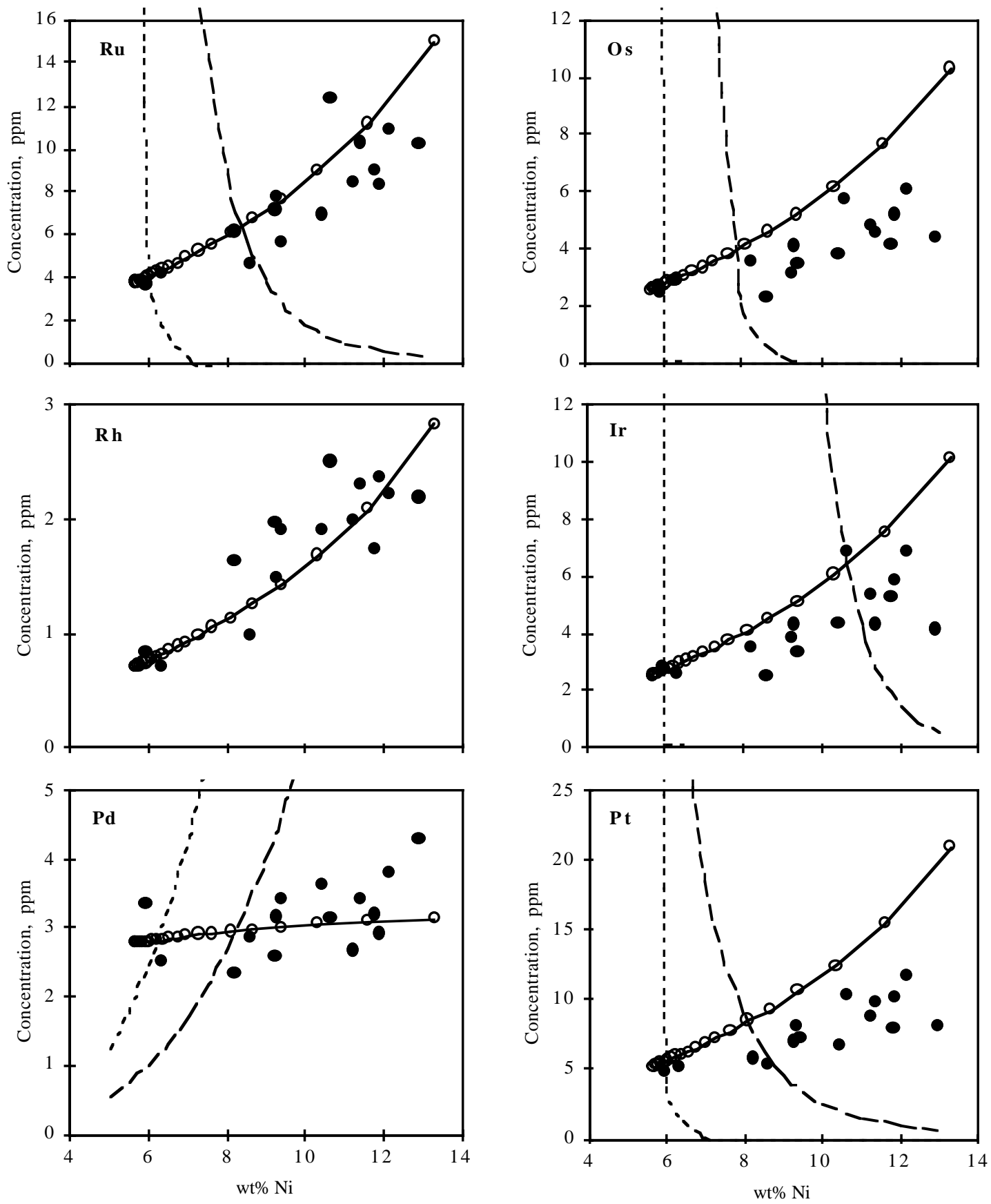
\#W0332: Campbell et al., Figure 7
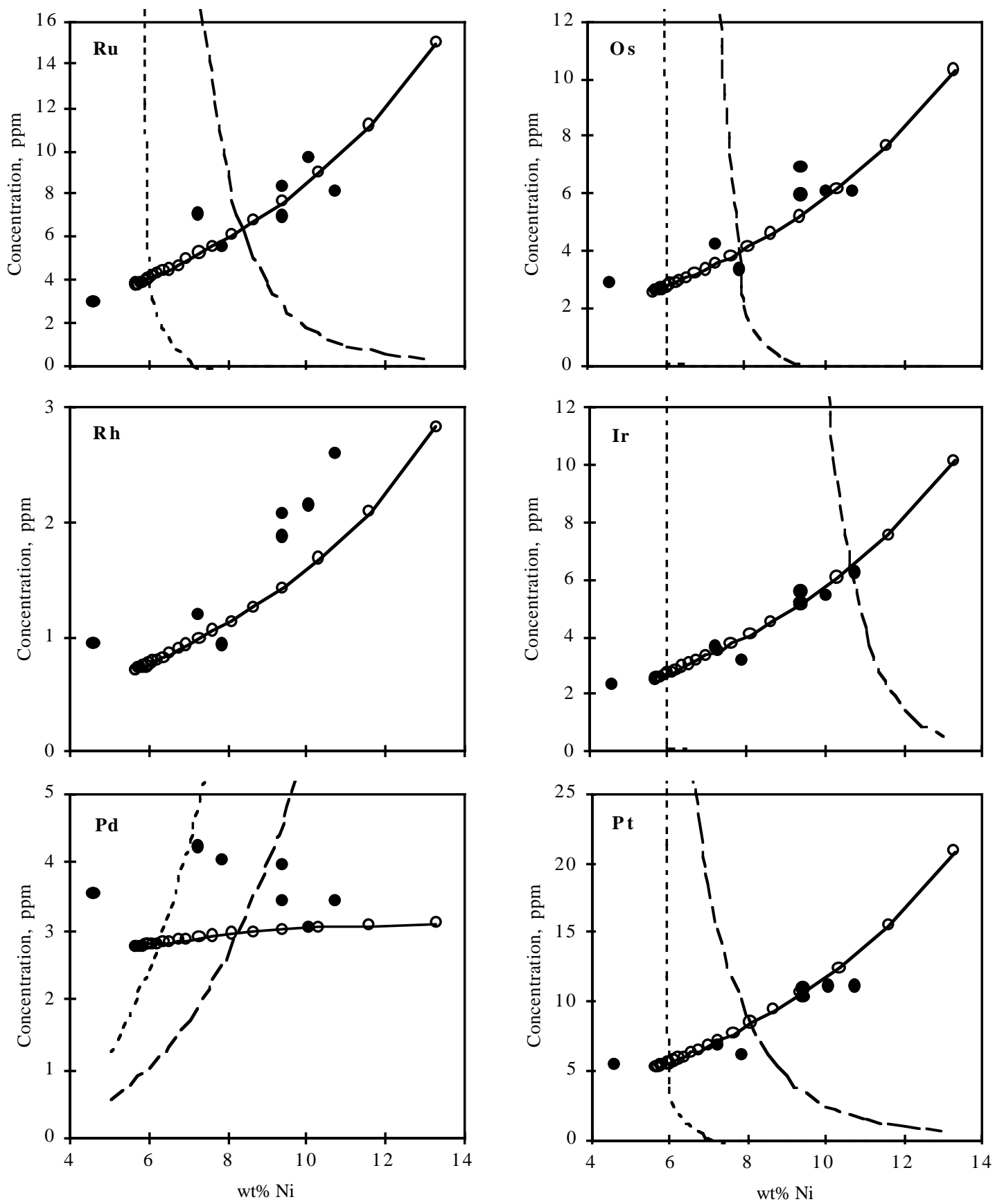
\#W0332: Campbell et al., Figure 8

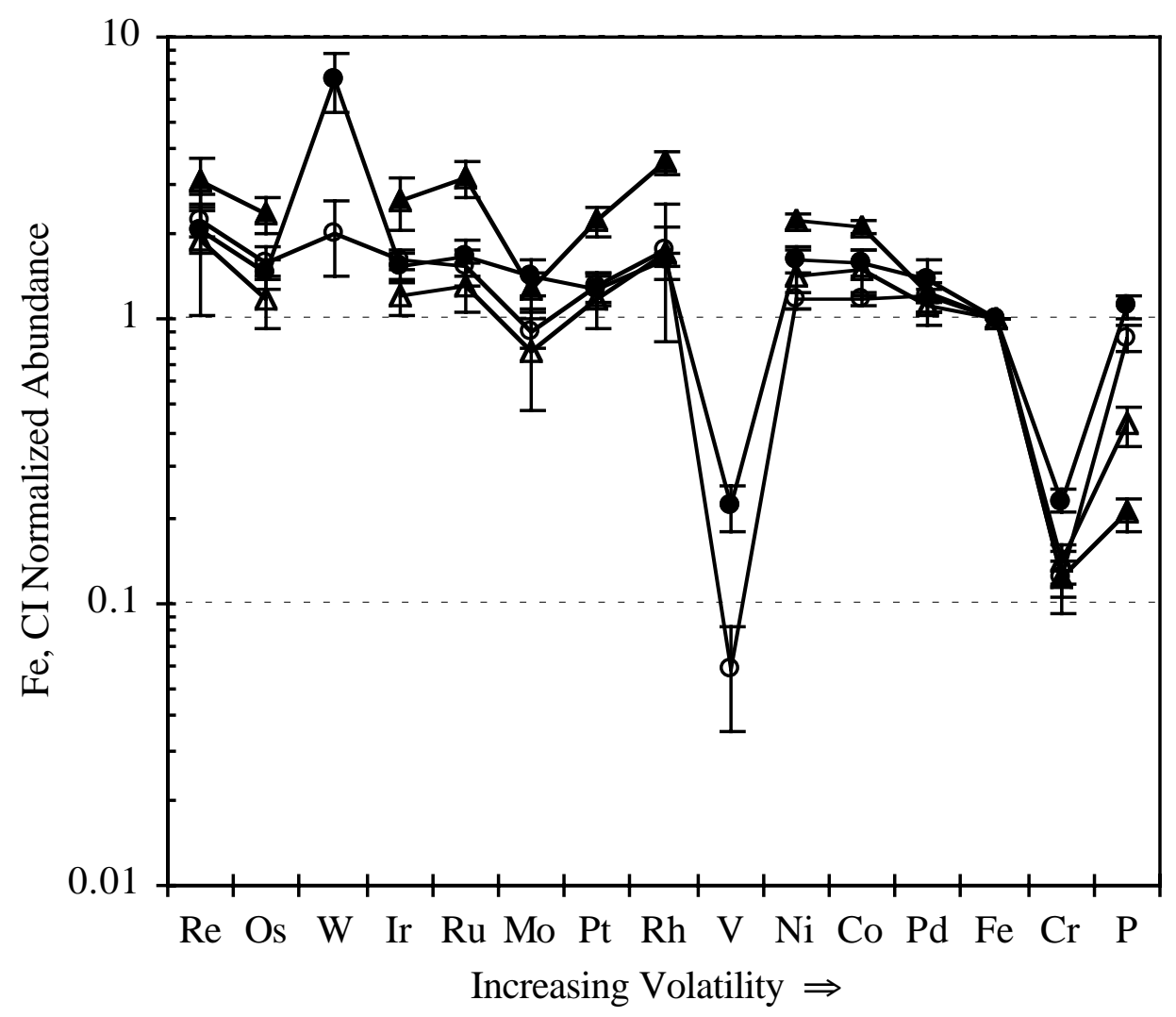




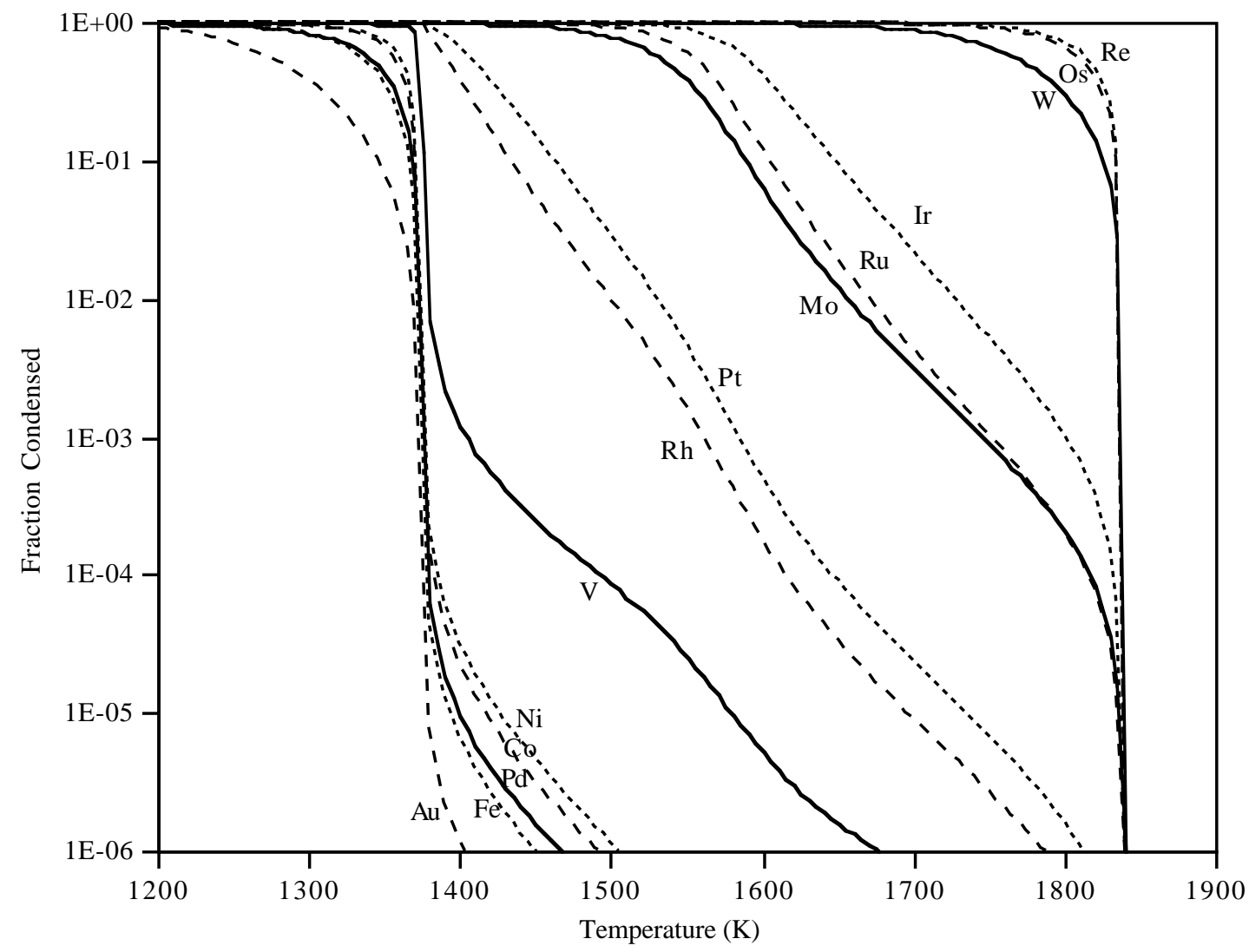


\#W0332: Campbell et al., Figure 10

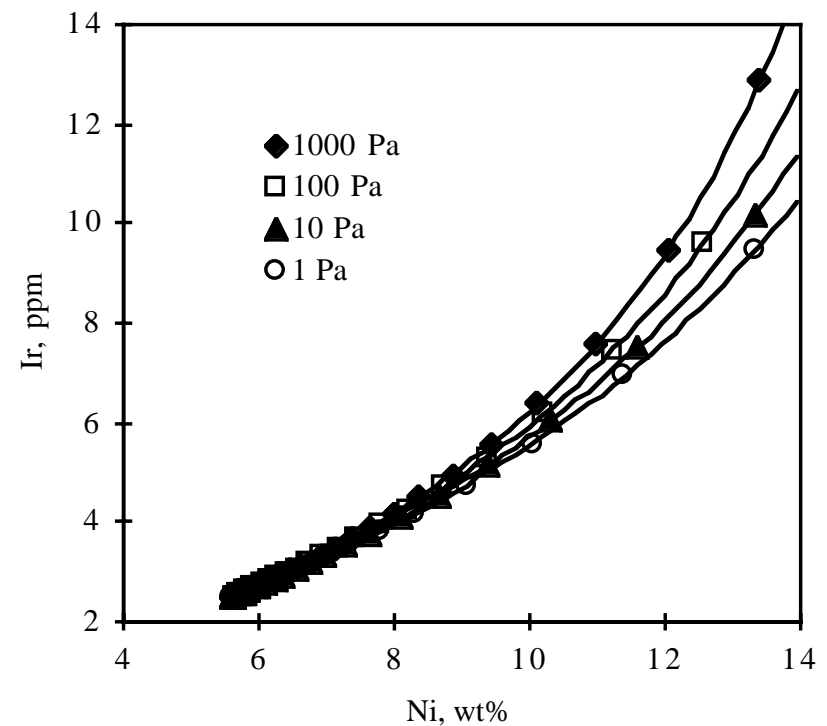




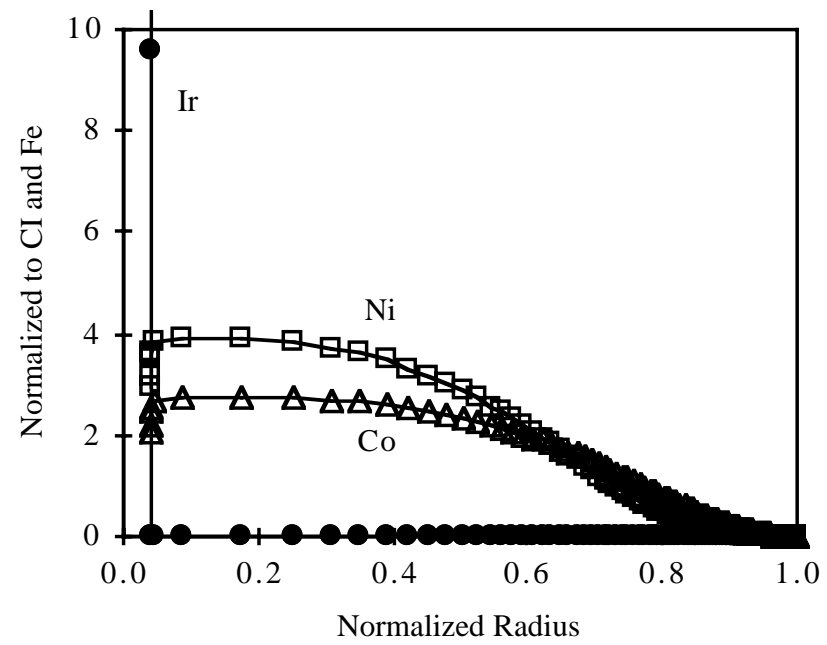




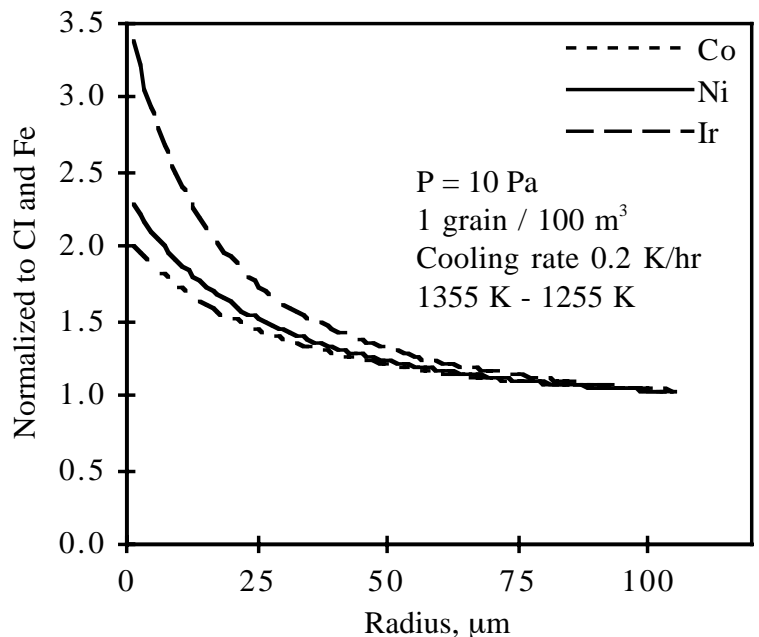

